\title{
Retrieval of aerosol complex refractive index from a synergy between lidar, sunphotometer and in situ measurements during LISAIR experiment
}

\author{
J.-C. Raut and P. Chazette \\ Laboratoire des Sciences du Climat et de l'Environnement, Laboratoire mixte CEA-CNRS-UVSQ, CEA Saclay, 91191 \\ Gif-sur-Yvette, France
}

Received: 1 November 2006 - Published in Atmos. Chem. Phys. Discuss.: 22 January 2007

Revised: 5 April 2007 - Accepted: 10 April 2007 - Published: 6 June 2007

\begin{abstract}
Particulate pollutant exchanges between the streets and the Planetary Boundary Layer (PBL), and their daily evolution linked to human activity were studied in the framework of the LIdar pour la Surveillance de l'AIR (LISAIR) experiment. This program lasted from 10 to 30 May 2005. A synergetic approach combining dedicated active (lidar) and passive (sunphotometer) remote sensors as well as ground based in situ instrumentation (nephelometer, aethalometer and particle sizers) was used to investigate urban aerosol optical properties within Paris. Aerosol complex refractive indices were assessed to be $1.56-0.034 \mathrm{i}$ at $355 \mathrm{~nm}$ and $1.59-0.040 \mathrm{i}$ at $532 \mathrm{~nm}$, thus leading to single-scattering albedo values between 0.80 and 0.88 . These retrievals are consistent with soot components in the aerosol arising from traffic exhausts indicating that these pollutants have a radiative impact on climate. We also discussed the influence of relative humidity on aerosol properties. A good agreement was found between vertical extinction profile derived from lidar backscattering signal and retrieved from the coupling between radiosounding and ground in situ measurements.
\end{abstract}

\section{Introduction}

It is now clearly recognized that anthropogenic aerosol particles play a substantial role in the radiative forcing of the earth's climate, as they influence the radiation balance of the Earth, mostly through scattering and absorption processes on both incoming and outgoing radiation and by acting as cloud condensation nuclei (e.g. D'Almeida et al., 1991; Ackerman

Correspondence to: J.-C. Raut

(jean-christophe.raut@cea.fr) and Chung, 1992; Lenoble, 1993; Léon et al., 2002). Nevertheless quantification of aerosol microphysical and optical properties and their dependency on relative humidity $(\mathrm{RH})$ is needed to reduce the large associated uncertainty (e.g. Penner et al., 1994; IPCC, 2001; Carrico et al., 2003). The correct modelling of radiative forcing by aerosols as well as the development of aerosol remote sensing techniques require a full range of observations. They include measurements of the aerosol chemical composition, number and/or mass size distribution, and optical properties to retrieve key parameters such as the spectral dependency of the aerosol complex refractive index (ACRI) (e.g. Sokolik and Toon., 1999; Sokolik et al., 2001). The determination of ACRI is often provided from bulk chemical compositions and known values of the refractive indices of pure compounds (e.g. Ouimette and Flagan, 1982; Hitzenberger and Puxbaum, 1993; Bond et al., 1998; Chazette and Liousse, 2001). The choice of this traditional approach is driven by the high dependency of ACRI on the aerosol chemical composition. Several studies focused on the determination of ACRI for dusts particles. Volz (1973) reported his laboratory experiments on bulk dust samples in the shortwave range and in the infrared spectral region. Patterson et al. (1977) used Saharan dust samples and laboratory measurements to produce one of the most widely used data sets of imaginary part of ACRI for mineral dust in the range $300-700 \mathrm{~nm}$. Ground based measurements in the spectral range from 0.5 to $1.0 \mu \mathrm{m}$ have also given the imaginary part of ACRI for desert dust (Sokolik et al., 1993; Carlson and Caverly, 1977; Tomasi et al., 1983). Marley et al. (2001) presented preliminary results for carbon soot samples generated in the laboratory and for standard diesel soot samples in the UV/visible spectral range. Remote sensing retrievals have been investigated by numerous authors (Kaufman et

Published by Copernicus GmbH on behalf of the European Geosciences Union. 
al., 2001; Dubovik et al., 2002; Sinyuk et al., 2003; Todd et al, 2005). Ignatov et al. (1995) proposed refractive index values from a validation using sun photometer measurements off the west coast of North Africa and in the Mediterranean Sea. Moulin et al. (1997) compared Meteosat-derived $(0.7 \mu \mathrm{m})$ and sun photometer-derived aerosol optical thicknesses to retrieve desert aerosol refractive index. Multiwavelength backscatter and extinction lidar measurements also enable to retrieve ACRI: a detailed description of such an inversion scheme has been given by Müller et al. (1999) and applied to pollution plumes advected from the European continent out over the Atlantic Ocean (Müller et al., 2002).

On the other hand, pollutants emitted in industrialised regions, particularly due to automobile traffic, are now clearly recognized as one of the most important source of anthropogenic aerosol particles and megacities emerge as an important research topic in atmospheric chemistry and effect on climate. Several experimental campaigns were conducted to document the atmospheric pollution in urban areas, for instance in Athens (Kambezidis et al., 1995; Durieux et al., 1998; Eleftheriadis et al., 1998), Los Angeles (Lurmann et al., 1997), Paris (Menut et al., 2000; Chazette et al., 2005b), Sao Paulo (Landulfo et al., 2003), Marseilles (Cros et al., 2004; Cachier et al., 2005). Local experimental studies focused on the microphysical, chemical and optical aerosol properties are clearly required to better characterize urban particles. Except scarce studies, e.g. a partial molar fraction approach (Stelson, 1990), little was known about urban ACRI. This work therefore focuses on their determination in the framework of an intensive one-month field campaign.

In this paper we present a retrieval method to infer urban aerosol optical properties in Paris PBL, particularly the complex refractive index at 355 and $532 \mathrm{~nm}$. This methodology relies on a synergetic approach using in situ and active/passive optical measurements. A field campaign has been used: the Lidar pour la Surveillance de l'AIR (LISAIR) experiment devoted to a better understanding of the exchanges of particulate pollutants between surface (streets) and the planetary boundary layer (PBL) took place in Paris during May 2005.

\section{Instrumental set-up}

LISAIR experiment was scheduled between 10 and 30 May 2005 and was located in Paris above town hall place. The geographic location of Paris, far from the coast, with a low topography, and far (about $200 \mathrm{~km}$ ) from other populated areas, makes this region an ideal place to study the respective contributions of dynamical and chemical processes to the photochemistry and to identify interactions between dynamics and air pollution. Two lidar systems were used and in situ instruments devoted to aerosol measurements (nephelometer, particle sizer, aethalometer) were simultaneously operated in a ground based mobile experimental station.

\subsection{Active remote sensing instruments}

Two lidar systems were used during LISAIR experiment. The lidar equation gives the range-corrected signal for the emitted wavelength as a function of the range, the total backscatter and extinction coefficients, a constant that characterizes the lidar system, the background sky radiance and the overlap function (Measures, 1984). The signal in the upper clear air is normalized on the molecular contribution that we derived from an ancillary climatic radiosounding database as in Chazette et al. (1995). The signal is corrected from the background sky radiance, which is simultaneously measured with the lidar profile. The overlap factor is a correcting factor for short-range heights where the field of view of the telescope does not overlap the laser beam. The overlap factor is measured as the difference at short range between the raw lidar measurements and the calculated lidar signal considering a homogeneous aerosol layer (Sicard et al., 2002; Chazette, 2003).

The lidar 'Lidar pour l'Etude et le Suivi de l'Aérosol Atmosphérique" (LESAA) has been developed by the Commissariat à l'Energie Atomique (CEA) to document the atmospheric reflectivity at $532 \mathrm{~nm}$ in the lower troposphere over polluted areas. LESAA uses sub-micron aerosols as a tracer to document the lower troposphere structure with a vertical resolution of $7.5 \mathrm{~m}$ (Chazette et al., 2005a). The sky background radiance is measured from the lidar signal at high altitude ( 45 to $55 \mathrm{~km}$ ) where the laser beam could be considered to be negligible. The lidar measurement is associated with an overlap factor close to 1 at $200 \mathrm{~m}$ above the ground level (a.g.l.). After correction, we retrieved the lidar signal until $\sim 50 \mathrm{~m}$ a.g.l. within a relative error close to $20 \%$ (Chazette et al., 2005b). Lidar signal is proportional to particle concentration so that lidar-derived atmospheric backscattering is generally observed to be large in the atmospheric boundary layer and in elevated aerosol layers inside the free troposphere (residual aerosol or dust aerosol layers). An example of the temporal evolution of LESAA aerosol extinction coefficient profiles is given on Fig. 1 for the 18 May 2005. The different sources of uncertainty are well described by Chazette et al. (1995). The mean relative error for the extinction coefficient is generally less than $10 \%$ when the inversion of lidar profiles is constrained using a sun photometer (Chazette, 2003) and when the relative humidity stays lower than $75 \%$, as it was the case here. The PBL height can be also retrieved from lidar measurements considering the radius of curvature of the profiles following Menut et al. (1999).

The lidar "Lidar Aérosol Ultra-Violet (Aéroporté)" (LAUV(A)) has been developed by the Commissariat à l'Energie Atomique (CEA) and the Centre National de la Recherche Scientifique (CNRS) to follow the aerosol dispersion in the street and through the PBL. It is compact, embarquable and eye safe and operates at the wavelength of $355 \mathrm{~nm}$ with a resolution along the line of sight of $1.5 \mathrm{~m}$. The lidar is associated with an overlap factor close to 1 at 
$100 \mathrm{~m}$ a.g.l. Further description of this instrument can be found on the website: (http://www.leosphere.fr.) It was used for the first time, in its operational mode during LISAIR experiment. The inversion of the $\operatorname{LAUV}(\mathrm{A})$ measurements is similar to those of LESAA measurements.

\subsection{Passive remote sensing instrument}

Optical thickness data were obtained from the AErosol RObotic NETwork (AERONET: http://aeronet.gsfc.nasa. gov/), from a station based in Pierre et Marie Curie University. The sunphotometer instrument performs integrated measurements of solar light extinction to retrieved aerosol optical properties (optical thickness and ACRI, at several wavelengths, and Angström exponent) (Holben et al., 1998). The channels used for this study are centred at $440 \mathrm{~nm}$ and $675 \mathrm{~nm}$. The AERONET database gives a maximal absolute uncertainty of 0.02 for the optical thickness, independent of the aerosol loading. The optical thickness $\tau$ at the lidar wavelength $\lambda$ has been assessed using the Angström exponent $a$ and the aerosol optical thickness at $440 \mathrm{~nm} \tau_{440}$ according to the Angström relation (Angström, 1964):

$\tau=\tau_{440} \cdot\left(\frac{\lambda}{440}\right)^{-a}$ where $a=\frac{\ln \left(\frac{\tau_{675}}{\tau_{440}}\right)}{\ln \left(\frac{440}{675}\right)}$

The complex refractive index retrieval, following Dubovik et al. (2000), can be obtained for aerosol optical thicknesses larger than 0.4 at $440 \mathrm{~nm}$ and is associated with an absolute error of 0.04 for the real part and a relative uncertainty of about $30 \%$ for the imaginary part (strongly absorbing aerosol). Optical thicknesses observed above Paris are however generally lower than 0.4 at $440 \mathrm{~nm}$ : the accuracy on complex refractive index is thus not guaranteed. The uncertainty on the Angström exponent has been shown to be 0.03 for aerosol optical thickness of 0.2 (Hamonou et al., 1999). Figure 2 shows optical thickness from AERONET data of level 2 and Angström exponent used in the following for 18 May .

\subsection{In situ measurements}

The three-wavelength $(450,550$ and $700 \mathrm{~nm})$ nephelometer (manufactured by TSI) was installed onboard the Mobile Aerosol Station (MAS). It measures the aerosol-scattering coefficient in a $7-170^{\circ}$ scattering angle range through a PM10 inlet head. To take into account the non-observed scattering angles, a correction factor has been assessed from Mie computations to be close to 1.020 for Paris urban aerosols. This assessment was done using the retrieved aerosol mean size number distribution and the mean complex refractive index on the 18 May 2005 (see Sect. 4 and Fig. 4). The three wavelength instrument scattering chamber was maintained at about $35-40 \%$ relative humidity (dry aerosol conditions). The mean relative uncertainty on the measurements

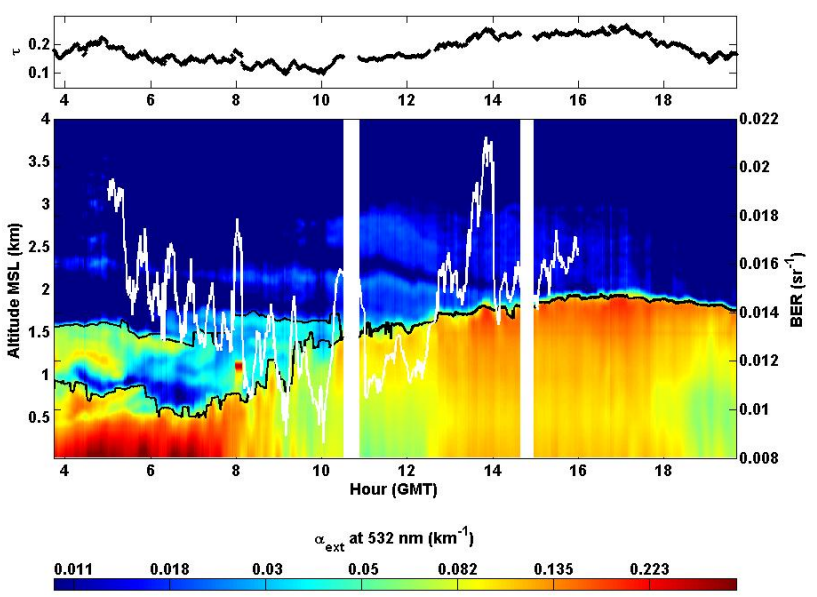

Fig. 1. Temporal evolution of the vertical profile of aerosol extinction coefficient at $532 \mathrm{~nm}$ above Paris on 18 May 2005 between 03:00 and 20:00 UTC. The upper part of the figure represents the corresponding total aerosol optical thickness. Both the PBL and the residual layer heights are given in a black curve. Daytime evolution of the BER at $532 \mathrm{~nm}$ is given in white.

is less than $10 \%$ and mainly due to the variability of the relative humidity inside the instrument (Bodhaine et al., 1991). In dry conditions, the relative uncertainty after calibration is around a few per cent (evaluated from the reproductibility of laboratory measurements). Angström exponent calculated from 450 and $550 \mathrm{~nm}$ channels is represented on Fig. 2. The difference observed with the sun photometer is mainly due to the spectral variability of the absorbing part of aerosols. Altitude dependence can also explain the different values of Angström parameter in Fig. 2 derived from the instruments.

The aethalometer instrument (manufactured by Magee Scientific Company) permitted the assessment of black carbon concentration (BC) within an average time of $2 \mathrm{~min}$. The atmospheric samplings were performed through a PM10 inlet head. The instrument, calibrated with a constant value of $19 \mathrm{~m}^{2} \mathrm{~g}^{-1}$, is sensitive to the light absorbent part of the aerosols (Hansen and Novakov, 1990). This specific crosssection is established for material trapped on the filter and is not valid for particles in the ambient atmosphere. Moreover, an artificial enhancement of the absorption coefficient by a factor $\approx 2$ could be found due to multiple scattering into the filter fibers (Bodhaine, 1995). During the LISAIR campaign the aethalometer measurements were calibrated using simultaneous black carbon concentration retrieved from coulometer analyses of filter samplings as described in Randriamiarisoa et al. (2006). According to Fig. 3, the calibration coefficient is 1.5 , which gives a final specific cross-section of $28.5 \mathrm{~m}^{2} \mathrm{~g}^{-1}$. The calibration of the aethalometer instrument on chemical filters has been carried out for mass concentrations averaged over the whole spectrum of aethalometer wavelengths, i.e. from 370 to $950 \mathrm{~nm}$. Relative uncertainty on the $\mathrm{BC}$ measurements performed with this instrument is 

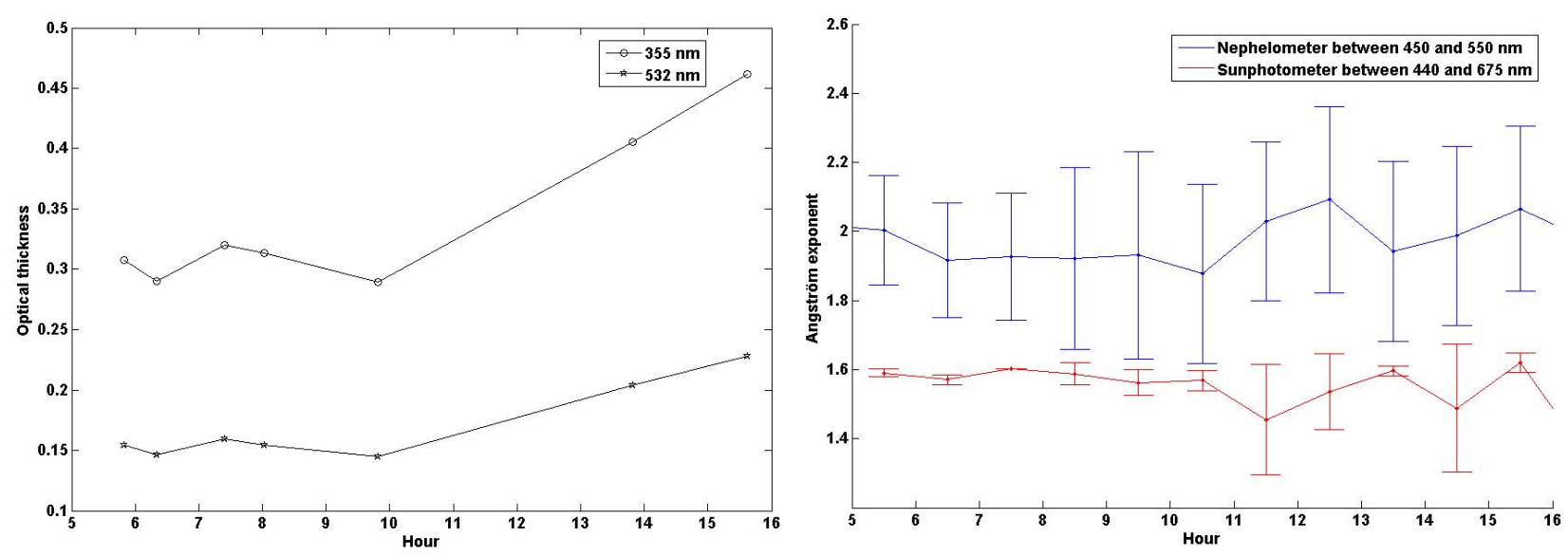

Fig. 2. Temporal evolution of aerosol properties retrieved from both AERONET and nephelometer data in Paris on 18 May 2005 . On the top (a), evolution of optical thickness at $355 \mathrm{~nm}$ and $532 \mathrm{~nm}$. On the bottom (b), evolution of the Angström exponent using 440 and $675 \mathrm{~nm}$ channels. Angström exponent deduced from nephelometer measurements is also represented. Vertical bars (b) indicate the standard deviation on hourly averaged data.

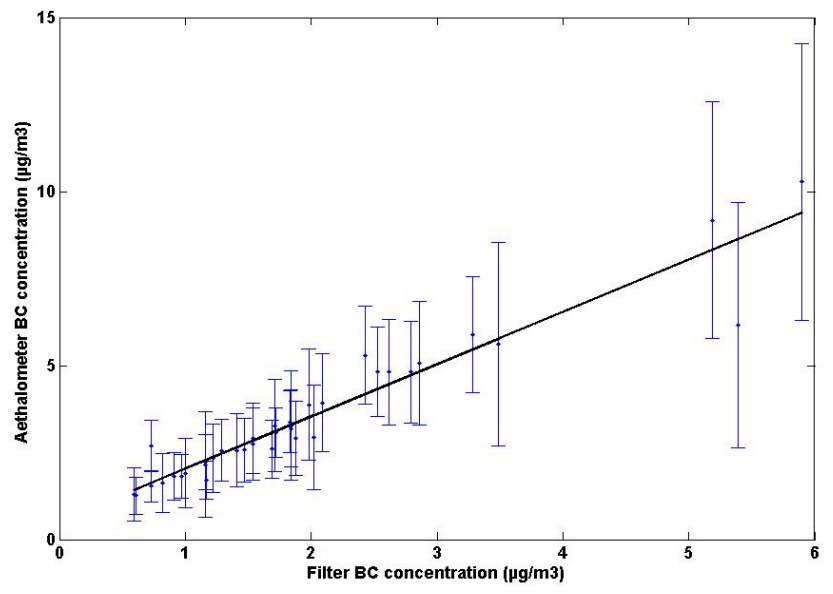

Fig. 3. Calibration curve of black carbon concentration measured by aethalometer $\left(\mathrm{BC}_{a}\right)$ against the black carbon concentration measured on filters $\left(\mathrm{BC}_{f}\right)$. Vertical bars indicate standard deviations on aethalometer measurements. The correlation ratio of this fitting is close to 0.96 for a linear law given by $\mathrm{BC}_{a}=1.5 \mathrm{BC}_{f}+0.54$.

close to $10 \%$ (Chazette et al., 2003). According to Bond et al. (1999), the instrument is found to interpret about $2 \%$ of the scattering as absorption; the measured absorption is about $22 \%$ higher than the reference absorption. This correction has been taken into account in this paper.

The Electrical Low Pressure Impactor (ELPI) is a realtime particle size spectrometer designed at the Tampere University of Technology (Delkati, Ltd., (http://www.dekati. com/elpi.shtml) for real-time monitoring of aerosol particle size distribution (Keskinen et al., 1992). The ELPI measures airborne particle size distribution in the size range from 0.028 to $10.03 \mu \mathrm{m}$ within 12 channels. The principle is based on charging, inertial classification, and electrical detection of the aerosol particles. The instrument consists primarily of a corona charger, low pressure cascade impactor and multichannel electrometer. It is used to retrieve the aerosol number size distribution at the surface level. The accuracy on the aerosol number concentration measurement is about $5 \%$, following manufacturer user manual.

\section{Backscatter-to-extinction ratio retrieval}

This part describes the contribution of our observations to a synergy between lidar, sun photometer and in situ measurements to retrieve the aerosol optical properties: scattering and extinction coefficients, ACRI, single-scattering albedo and backscatter-to-extinction ratio (BER), inverse of the so called lidar ratio. The procedure we used is shown on Fig. 4 and fully described below.

Lidar data have been inverted using a well-known method, based on Bernoulli's differential form of the propagation equation (Klett, 1981). The backscatter lidar equation is underdetermined due to its dependence on the two unknowns, backscatter coefficient and extinction coefficient (e.g. Klett, 1981, 1985; Hughes et al., 1985; Sasano et al., 1985; Bissonnette, 1986; Kovalev, 1993; Chazette et al., 1995). Sun photometer measurements were then used to constrain the lidar inversion. It was thus possible to determine an equivalent BER of the entire aerosol vertical column with an iterative procedure (Chazette, 2003), while varying BER between 0.005 and $0.055 \mathrm{sr}^{-1}$, which includes the most probable values for aerosols in an urban area. This procedure is considered convergent when the variation between sun photometer and lidar derived aerosol optical thicknesses is lower 


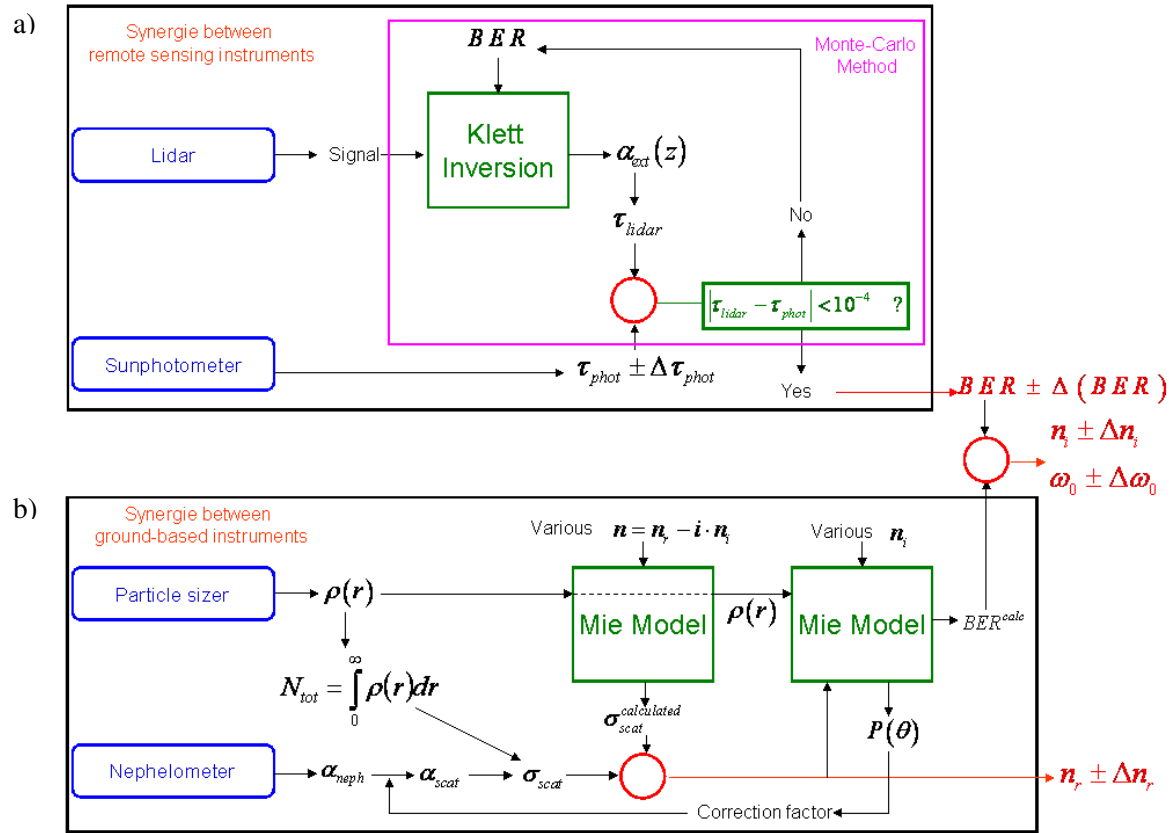

Fig. 4. Schema of the synergetic approach to retrieved aerosol optical properties: backscatter-to-extinction ratio BER (a), complex refractive index (real $n_{r}$ (b) and imaginary $n_{i}$ parts), single-scattering albedo $\omega_{0}$ from optical thicknesses ( $\tau_{\text {phot }}$ for sunphotometer and $\tau_{l i d a r}$ for lidar, integrating extinction coefficient $\left.\alpha_{\text {ext }}(z)\right)$, number size distribution $\rho(r)$ and scattering-cross section $\sigma_{s c a t}$. Scattering cross-section is the ratio between scattering coefficient $\alpha_{\text {scat }}$, obtained from nephelometer scattering coefficient $\alpha_{\text {neph }}$ and phase function $P(\theta)$, and the total number of particles $N_{\text {tot }}$.

than $10^{-4}$ (Fig. 4). The result is not dependant of this initial value chosen to be $0.014 \mathrm{sr}^{-1}$. The iterative method is determined by a dichotomist approach where BER is increased (decreased) if the lidar-derived optical thickness is larger (lower) than the sun photometer-derived optical thickness (see Fig. 4a).

The histogram of the aerosol backscatter-to-extinction ratio assessed from daytime lidar measurements is reported in Fig. 5. Optical thickness values used to constrain each lidar profile inversion have been averaged on a one-hour basis. BER values are distributed following an almost Gaussian curve. The mean value calculated for the significant values (low rate of relative humidity) of BER is close to $0.014 \mathrm{sr}^{-1}$ (respectively $0.012 \mathrm{sr}^{-1}$ ) with a standard deviation of $0.002 \mathrm{sr}^{-1}$ (respectively $0.003 \mathrm{sr}^{-1}$ ) at $532 \mathrm{~nm}$ (respectively $355 \mathrm{~nm}$ ). The BER temporal evolution at $532 \mathrm{~nm}$ is also given in Fig. 1 and its variability can be likely ascribed to convective movements in the PBL whose oscillations stem from thermal phenomena. Figure 6 gives the hourly average of the BER at 355 and $532 \mathrm{~nm}$ retrieved from the synergy between lidar and sunphotometer, and from the sunphotometer alone on 18 May. Uncertainties on BER retrieval will be discussed in Sect. 5.

According to other measurements reported in literature, BER values lie between 0.010 and $0.018 \mathrm{sr}^{-1}$ in a polluted boundary layer over Leipzig in Germany and between 0.014

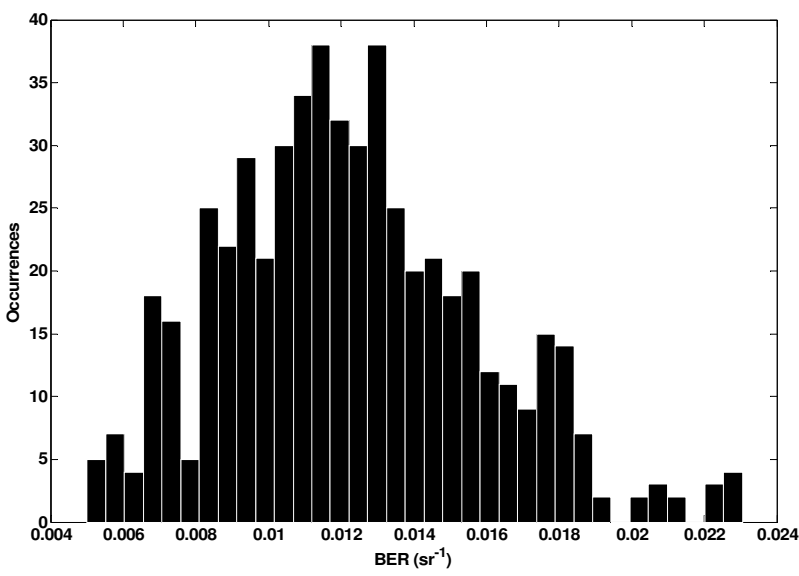

Fig. 5. Histogram of the aerosol backscatter-to-extinction ratio (BER) assessed from the synergy between lidar and sunphotometer measurements at $355 \mathrm{~nm}$ on 18 May 2005.

and $0.030 \mathrm{sr}^{-1}$ in the polluted centre of the United States. Those results are referred by Anderson (2000). Cattrall et al. (2005) employed ground based retrievals of aerosol properties from the global aerosol network AERONET for several urban and industrial locations and found lidar ratios (1/BER) at $550 \mathrm{~nm}: 74 \mathrm{sr}$ in Aire Adour (France), $74 \mathrm{sr}$ in 
Table 1. Mean complex refractive index determined on the ground and with AERONET station in Paris. The temporal variability is given under brackets and the uncertainties under parenthesis. Both have been calculated as standard deviations.

\begin{tabular}{llll}
\hline Wavelength & Real part of index & Imaginary part of index & Single-scattering albedo \\
\hline $355 \mathrm{~nm}$ & $1.561(0.017)$ & $0.028(0.009)$ & $0.879(0.036)$ \\
$532 \mathrm{~nm}$ & $\{0.111\}$ & $\{0.013\}$ & $\{0.063\}$ \\
& $1.587(0.009)$ & $0.044(0.004)$ & $0.797(0.015)$ \\
$441 \mathrm{~nm}$ (Aeronet) & $\{0.112\}$ & $\{0.026\}$ & $\{0.097\}$ \\
& $1.424(0.04)$ & $0.041(0.012)$ & $0.774(0.030)$ \\
$673 \mathrm{~nm}$ (Aeronet) & $1.099\}$ & $\{0.026\}$ & $\{0.072\}$ \\
& $\{0.055\}$ & $0.036(0.010)$ & $0.739(0.030)$ \\
\hline
\end{tabular}
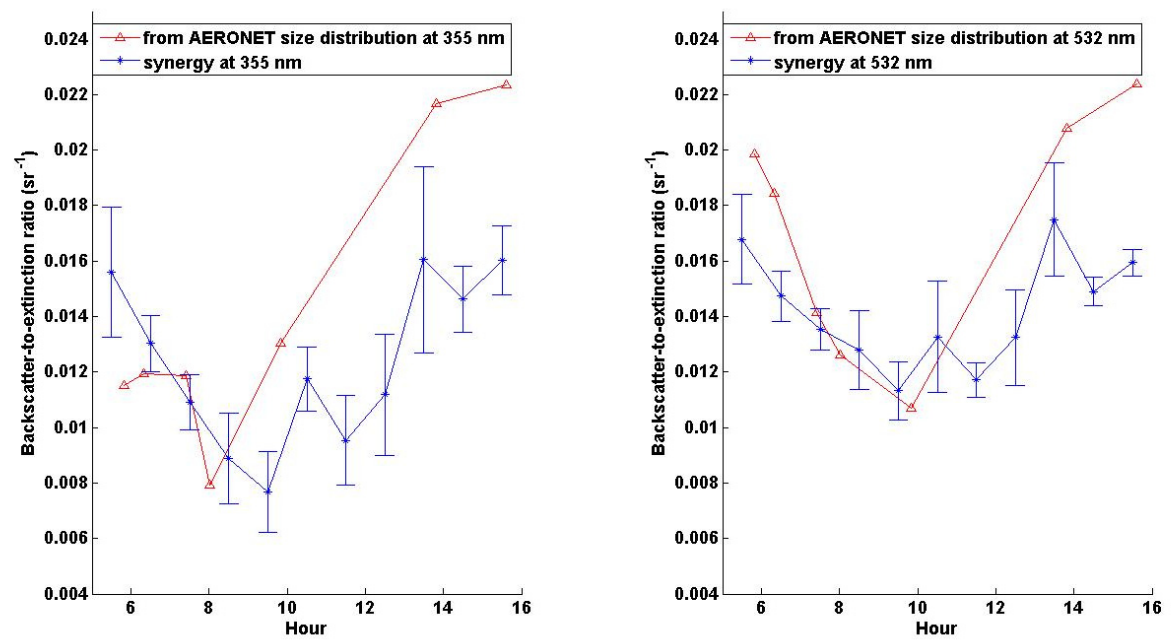

Fig. 6. Daytime evolution of BER on 18 May retrieved from the synergy between lidar and sun photometer at $355 \mathrm{~nm}$ (left) and $532 \mathrm{~nm}$ (right) and from AERONET data (channels $441 \mathrm{~nm}$ and $673 \mathrm{~nm}$ ) using Mie calculation based on AERONET size distribution and complex refractive index given in Table 1 . Vertical bars are the standard deviation on hourly averaged data.

Créteil (France), 76 sr in Lille (France), 72 sr in GISS (USA), $73 \mathrm{sr}$ in GSFC (USA) and $70 \mathrm{sr}$ in Mexico City (Mexico). These values are in very good agreement with our lidar ratio at $532 \mathrm{~nm}(71 \mathrm{sr})$. A BER close to $0.014 \mathrm{sr}^{-1}$ for anthropogenic aerosols at $532 \mathrm{~nm}$ as retrieved in our study, reminds the presence of a predominant fine mode in size distribution mainly due to automobile traffic sources. This BER is consistent with the value of about $0.014 \mathrm{sr}^{-1}$ found in Paris area at $532 \mathrm{~nm}$ within the framework of the ESQUIF program where airborne lidar measurements were performed (Chazette et al., 2005b). The BER value associated to prevailing automobile traffic pollution is in the range $0.013-0.018 \mathrm{sr}^{-1}$ as shown by Chazette et al. (2002) from summertime measurements over Paris. It mainly corresponds to aerosols constituted of carbonaceous core coated with non-absorbent material.

\section{Aerosol complex refractive index (ACRI) and single- scattering albedo retrievals}

Despite its relative importance, there have been only a few attempts to estimate ACRI from aerosol optical properties. Takamura et al. (1994) obtained an estimate of the imaginary part for tropospheric aerosols after assuming a real part, whereas Ferrare et al. (1998) focused on the retrieval of the real part of ACRI from a combination of scanning Raman lidar with simultaneous airborne aerosol in situ distribution measurements. In the following we present our approach to retrieve the ACRI using the synergy between remote sensing and in situ measurements.

\subsection{Real part of the refractive index}

The real part of ACRI has been assessed using both in situ particle sizer and nephelometer measurements. We have used the nephelometer measurements at 450 and $550 \mathrm{~nm}$ to re- 
trieve the scattering coefficient at the lidar wavelength of 355 and $532 \mathrm{~nm}$ following the Angström law. Various real parts $n_{r}$ between 1.3 and 1.9 and imaginary parts $n_{i}$ between $10^{-8}$ and 0.2 have been considered as input values of a look-up table. This table contains scattering cross-sections deduced from Mie theory that will be compared to the measured crosssection, as described on Fig. 4. Calculations have been performed considering spherical aerosols. Such an aspect could be validated when regarding the lidar depolarized ratio that has been found to be close to $4 \%$ in the PBL. The lognormal aerosol size distribution has been fitted using an approach well described in Randriamiarisoa et al. (2006) from the measurements of the particles sizers. Mainly a bimodal size distribution has been retrieved including the nucleation and accumulation modes. The contribution of a coarse mode was not significantly observed. We neglected the nucleation mode in optical computations since its contribution to scattering efficiency is smaller than 5\%, which is lower than uncertainties calculated on scattering-cross sections (Chazette et al., 2005b). An example of the comparison between the look-up table and the aerosol cross-section derived from the measurements is given in Fig. 7 for 18 May between 12:00 and 13:00 UTC for the lidar wavelength of $532 \mathrm{~nm}$. Note that 18 May is representative of the mean daily conditions of the LISAIR campaign. In the likely range of the imaginary part of the complex refractive index (between $10^{-8}$ and $5.10^{-2}$ ), the real part can be assessed to be close to 1.533 with a standard deviation of $\sim 0.008$. Indeed, the observed dispersion is very weak for imaginary parts lower than 0.05 , which is a plausible domain for anthropogenic aerosols from automobile traffic (Chazette et al., 2005b). Such an approach has been generalized to follow the temporal evolution of the real part of ACRI for 18 May given in Fig. 8.

4.2 Imaginary part of the refractive index and singlescattering albedo

The determination of the imaginary part of ACRI and the single-scattering albedo relies on a comparison between the previous BER used to invert lidar data and different values of BER calculated from size distribution with the real part retrieved from the look-up table (Fig. 9). This comparison requires a second use of Mie model (Fig. 4). The representativeness of in situ measurements of the aerosol aloft is ensured if the relative humidity does not significantly vary between the surface layer and the mixed layer: the humidity rate is low on the surface $(\approx 28 \%)$ and following the radiosoundings of Trappes (located at the Southwestern part of Paris suburb) does not exceed $60 \%$ on the top of the boundary layer. From lidar measurements, neither clouds nor dust layers have been observed over the PBL on 18 May 2005.

As a result on 18 May between 12:00 and 13:00 UTC, the imaginary part of the complex refractive index has been assessed to be $0.032 \pm 0.003$, and the single-scattering albedo is $0.82 \pm 0.01$. The temporal evolution of the imaginary part of

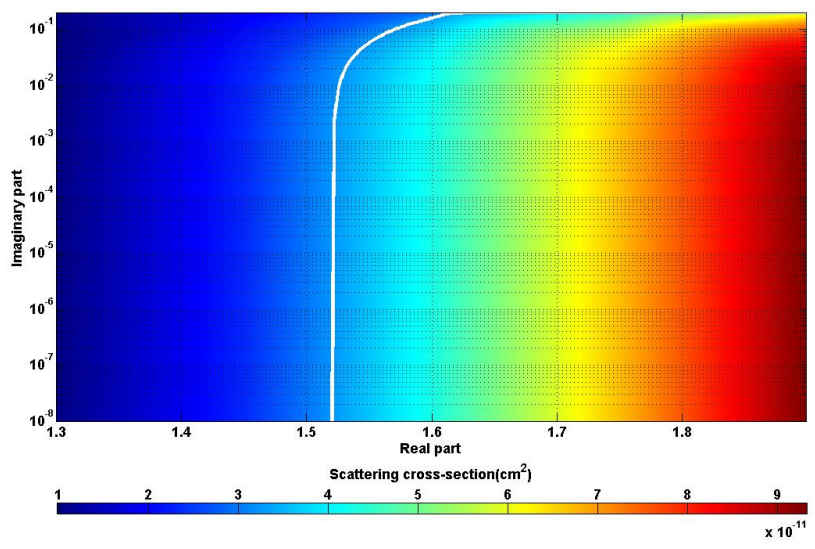

Fig. 7. Aerosol scattering cross-sections calculated for various real and imaginary parts of the complex refractive index (colour bar associated to the look-up table) at the wavelength of $532 \mathrm{~nm}$. The mean value of the scattering cross section retrieved from in situ measurements $\left(3.3710^{-11} \mathrm{~cm}^{2}\right)$ is also given in white for 18 May between 12:00 and 13:00 UTC.

ACRI is also given in Fig. 10. The associated single scattering albedos are given in Fig. 11. The single scattering albedo generally decreases when the wavelength increases for pollution aerosols as shown by Randriamiarisoa et al. (2004), with mean values of 0.88 at $355 \mathrm{~nm}$ and 0.80 at $532 \mathrm{~nm}$ (Table 1).

Aethalometer measurements can besides enable to independently assess the mean value of the ACRI imaginary part considering real parts calculated in the previous section. A closure study, based on a comparison between the specific absorption cross-section computed on the one hand through a Mie model and given on the other hand by the aethalometer $\left(28.5 \mathrm{~m}^{2} \mathrm{~g}^{-1}\right.$, Sect. 2.3$)$, has been performed. The latter can be considered as an equivalent specific cross-section for the equivalent wavelength of the aethalometer, which is about $550 \mathrm{~nm}$. The imaginary part retrieved from this approach $(0.055 \pm 0.004)$ is found in accordance with results given in Table 1 at $532 \mathrm{~nm}$ considering the natural variability of ACRI imaginary part (Fig. 10). This high value is however very close to maximum values obtained in the synergy presented in this article. No variability has been observed in retrievals on average using aethalometer (see Fig. 3). Due to calibration issues and problems regarding the overestimation of absorption by parasitic scattering effects and the spectral dependency, high uncertainties are expected when determining the imaginary part of ACRI by aethalometer.

\subsection{Discussion}

The AERONET website has provided data over Paris in May 2005 for ACRI. Averages and standard deviations are given in Table 1. Retrievals at the lidar wavelength of 355 and $532 \mathrm{~nm}$ have been compared to the real part of ACRI obtained from AERONET database (Fig. 8). $n_{r}$ does not significantly vary with the wavelength according to Table 2 , where 

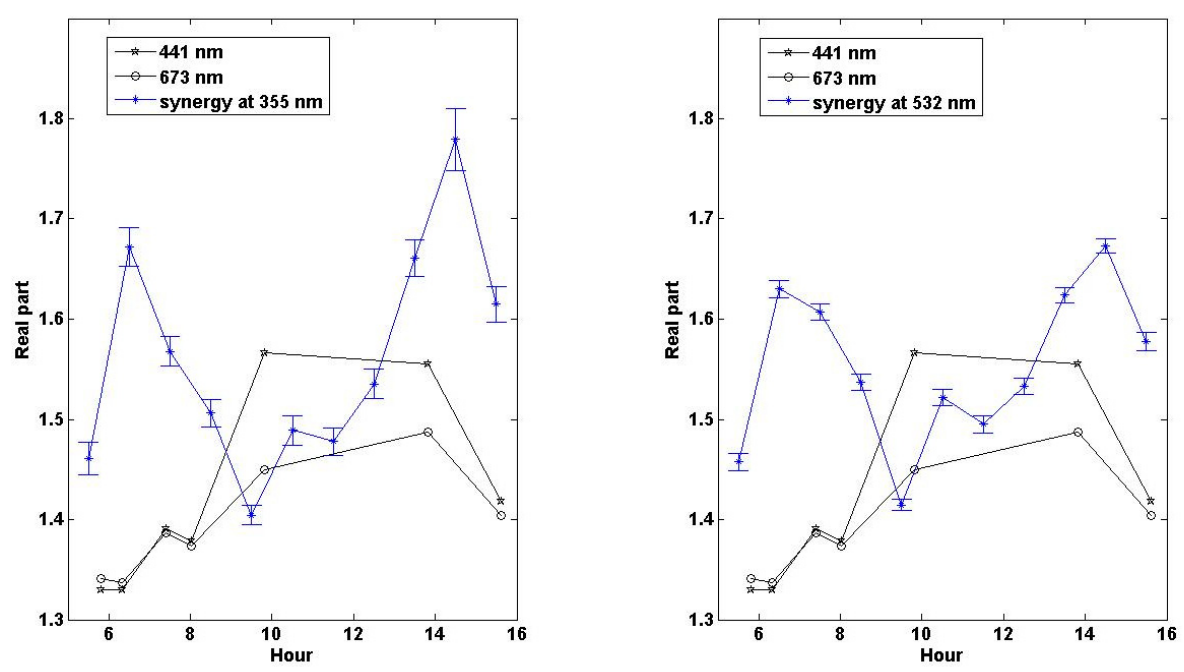

Fig. 8. Daytime evolution of the real part of ACRI $\left(n_{r}\right)$ retrieved from the synergy between lidar, sun photometer and in-situ instruments at $355 \mathrm{~nm}$ (left) and $532 \mathrm{~nm}$ (right) and from AERONET data (channels $441 \mathrm{~nm}$ and $673 \mathrm{~nm}$ ). Vertical bars are the standard deviation on hourly averaged data.

Table 2. Real aerosol refractive index determined on the ground level for different periods on 18 May 2005. The error on the restitution of these values is 0.01 .

\begin{tabular}{llll}
\hline Wavelength & $05: 00-06: 00$ & $12: 00-13: 00$ & $15: 00-16: 00$ \\
\hline $450 \mathrm{~nm}$ & 1.52 & 1.45 & 1.57 \\
$550 \mathrm{~nm}$ & 1.54 & 1.46 & 1.58 \\
$700 \mathrm{~nm}$ & 1.61 & 1.49 & 1.64 \\
\hline
\end{tabular}

real parts have been calculated for the three wavelengths of the nephelometer: 450,550 and $700 \mathrm{~nm}$ for different periods. $n_{r}$ values provided by AERONET are markedly lower $(<1.43)$ than our results, and depart farther from data in the reported literature (1.5-1.6). In addition, a higher value for the real part is more common in the previous literature for ambient soot, a crucial component of urban aerosols influencing the real part of the total refractive index: a value of 1.75 is reported by d'Almeida et al. (1991) and 1.95 by Ackerman and Toon (1981) and Faxvog and Roessler (1978). The discrepancy between our result and that of AERONET is important before 09:00 UTC and after 14:00 UTC. The discrepancy is larger for the imaginary part (Fig. 10) in the same temporal period than for the real part. Nevertheless, the assessments at the lidar wavelength of $532 \mathrm{~nm}$ seem to be in a better agreement, with close average values in the visible spectral range (Table 1).

The previous difference observed comparing to AERONET data may be due to the fact that AERONET retrieval algorithm characterizes the column aerosol properties using a fixed effective ACRI (Dubovik et al., 2002), i.e. the

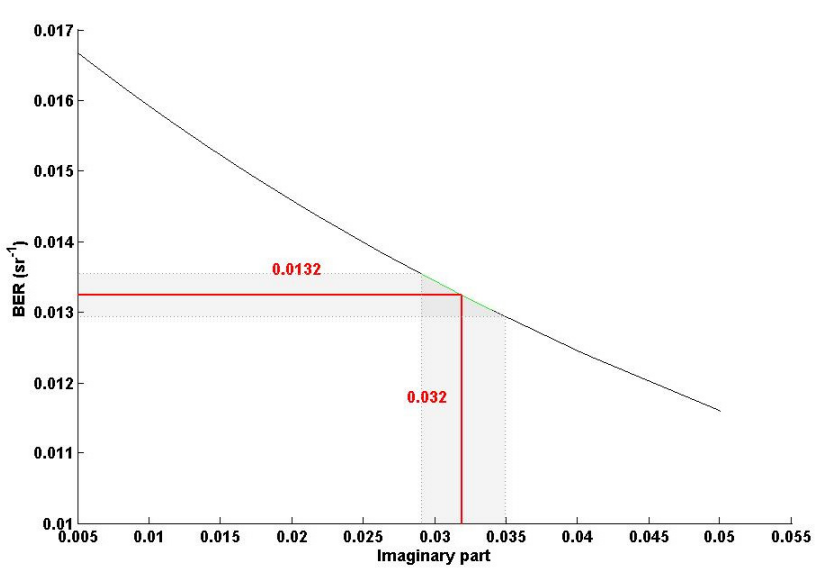

Fig. 9. Imaginary part of the complex refractive index at $532 \mathrm{~nm}$ retrieved from a mean value of BER between 12:00 and 13:00 UTC on 18 May. The gray band wrapping the curve represents the uncertainty on the retrieved value.

refractive index that would provide the same radiance on the basis of particle size distribution for homogeneous, spherical aerosols. Obviously, the ACRI derived from AERONET are averaged through PBL and are therefore lower than ACRI retrieved from in situ measurements that deal with ground level measurements. This effective complex index of refraction does not refer to any specific aerosol type but is suitable to quantify the composite radiative properties of all aerosols in an atmospheric column. Aerosols in urban areas are however complex and are generally a mixture of several chemical components including organic carbon, soot, water soluble, dust and sea salt (e.g. Higurashi and Nakajima, 

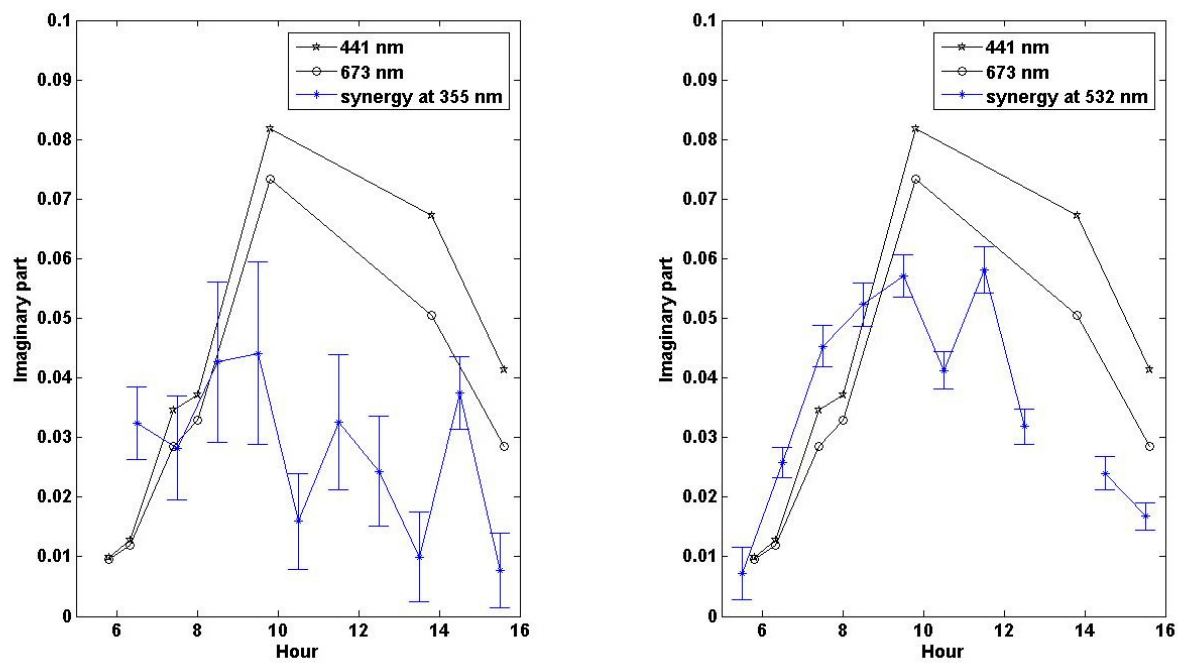

Fig. 10. Daytime evolution of $n_{i}$ retrieved from the synergy between lidar, sun photometer and in-situ instruments at $355 \mathrm{~nm}$ (left) and $532 \mathrm{~nm}$ (right) and from AERONET data (channels $441 \mathrm{~nm}$ and $673 \mathrm{~nm}$ ). Vertical bars are the standard deviation on hourly averaged data.
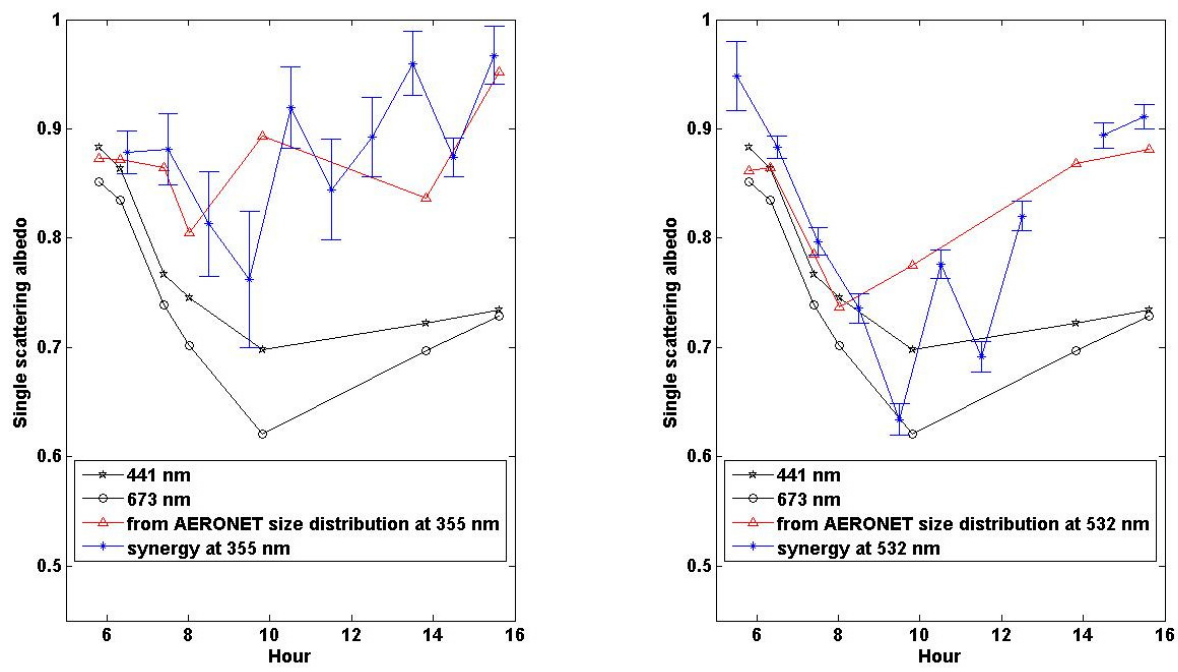

Fig. 11. Daytime evolution of single-scattering albedo on 18 May retrieved from the synergy between lidar and sun photometer at $355 \mathrm{~nm}$ (left) and $532 \mathrm{~nm}$ (right) and from AERONET data (channels $441 \mathrm{~nm}$ and $673 \mathrm{~nm}$ ) using Mie calculation based on AERONET size distribution and complex refractive index given in Table 1 . Vertical bars are the standard deviation on hourly averaged data.

2002). Depending on the chemical compositions of aerosols, the ACRI is highly variable (d'Almeida et al., 1991). The accuracy of AERONET is, moreover, not guaranteed in this case since optical thicknesses are too low; version 2 derived inversion data need to be processed with a modified algorithm.

In addition, ACRI determined in this study are coherent to those retrieved by other authors. For instance, Kent et al. (1983) concluded 1.60-0.15 i for urban aerosols. Most traditional studies based on bulk chemical analyses turned out to be reasonable approaches for approximation of the real part of the particle refractive index (1.5-1.6), but large differ- ences in reported imaginary parts, e.g. from 0.0007 to 0.0015 for desert dust and oceanic aerosols, exist even for the same type of aerosol (d'Almeida, 1987; Sokolik et al., 1993; Kaufman et al,. 2001; Wang et al., 2003). The corresponding values for calculation of the imaginary part are not as well known as their real counterparts. On the other hand, comparison with imaginary parts introduced in models may be ambiguous since the measured values depart farther from calculated values if the chemical composition consists of mixtures that are internal rather than external (Liousse et al. 1993). A good agreement is also found with Ebert et al. (2004). Thanks to his chemical analyses he found that urban influ- 


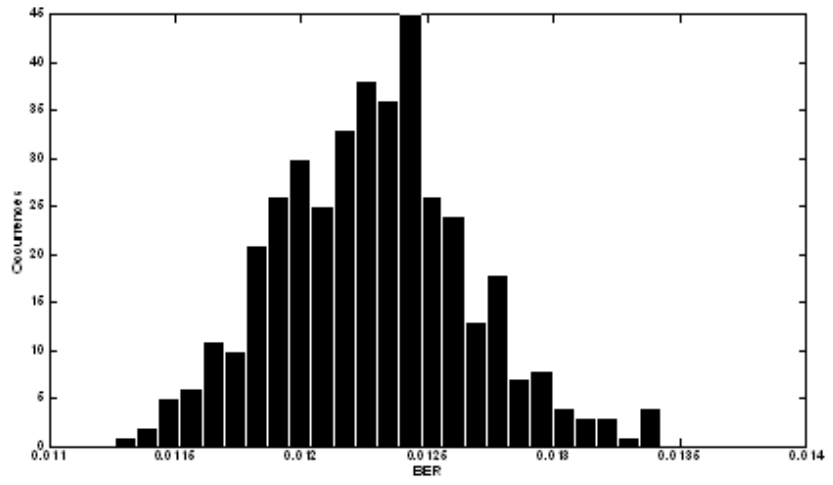

Fig. 12. Histogram of the aerosol backscatter-to-extinction ratio (BER) retrieved from a Monte-Carlo method at $532 \mathrm{~nm}$ for the mean lidar profile on 18 May between 12:00 and 13:00 UTC.

enced air masses are characterized by high real (1.60-1.73) and imaginary parts $(0.034-0.086)$ of the total ACRI. Ebert et al. (2004) suggested that high real parts of polluted air masses are predominantly caused by the high abundance of metal oxide/hydroxide particles, the high imaginary parts by high abundances of soot.

AERONET single-scattering albedo around 0.75 is low compared with other results (Kilsby and Smith, 1987; Moores, 1982; Kitchen and Squires, 1984): their results were over 0.8. However a Mie computation using the ACRI retrieved from this work on the ground level and AERONET number size distribution (Fig. 11) gives a single-scattering albedo coherent with our value determined on the ground $(0.80-0.88)$. The ranges found in this present study with their relative errors therefore include the values deduced from AERONET size distribution at 355 and $532 \mathrm{~nm}$. The agreement between our result on single-scattering albedo and the AERONET retrieval is of course better for the lidar visible wavelength of $532 \mathrm{~nm}$. Note that for the assessment of the optical thickness at $355 \mathrm{~nm}$ we have supposed that the Angström exponent is constant between the visible domain and this wavelength. This may affect our result because Mie calculation shows a value of $\sim 25 \%$ less between the wavelength couple of $(441,673)$ and $(355,532) \mathrm{nm}$ using the aerosol model retrieved at the ground level. Then, the ACRI at $355 \mathrm{~nm}$ may be underestimated. Mallet et al. (2003) found $0.85 \pm 0.5$ in South of France during Escompte campaign, Bergin et al. (2001) reported 0.81 on Beijing. Our results are also in very good agreement with Baumgardner et al. (2000) who carried out a recent study in Mexico-City using nephelometer and aethalometer indicating a value between 0.8 and 0.88. During the ESQUIF program in July 2000, Chazette et al. (2005b) found a single scattering albedo at $550 \mathrm{~nm}$ exhibiting a mean value ranging from 0.85 to 0.92 . This value was close to the mean AERONET value of $0.87 \pm 0.068$.
Following the work of Chazette et al. (2005a), we have also used the synergy between in situ and lidar/sunphotometer measurements in the framework of the Pollution dans les Vallées Alpines (POVA) experiment that took place in the alpine valleys of Chamonix in summer 2003. The same in situ and remote sensing measurements were performed during this campaign. The main aerosol sources are similar as Paris traffic ones. Calculations have given $1.48 \pm 0.05$ and $0.042 \pm 0.01$ for the real and the imaginary parts of the aerosol complex refractive index, respectively. The single scattering albedo has been found between 0.75 and 0.85 . These findings are consistent with carbonaceous (soot) components in the aerosol which is a very strong absorber of solar radiation, arising from vehicle exhausts due to the heavy traffic around the city.

\section{Sensitivity study}

The uncertainties on both the ACRI and the single-scattering albedo are mainly due to those on both BER and on scattering cross-section. The relative uncertainty on the scattering cross-section depends on the statistical fluctuation of number size distribution and scattering coefficient measured by the nephelometer. It has been found to be close to $10 \%$.

The uncertainty on BER retrieval has been characterized by the resulting bias and standard deviations on both the lidar-retrieved extinction coefficient and the sun photometer optical thickness. Errors related to lidar signal are negligible versus other errors because about 20000 profiles are averaged during an hour. The molecular model has been considered as inducing a relative uncertainty of $2 \%$ on the molecular backscatter coefficient. The bias and the standard deviations on the BER have been calculated using a Monte Carlo procedure illustrated in Fig. 4 as in the work of Chazette et al. (2002). They have been obtained from 400 random realizations for each error source, which thus ensures a normal distribution around the mean value. The uncertainty $\sigma(\tau)$ on the reference optical thickness value $\tau$ at wavelength $\lambda$ has been calculated using the following equation:

$\sigma(\tau)=\tau \cdot\left(\left(\frac{\sigma\left(\tau_{1}\right)}{\tau_{1}} \cdot\left(1+\frac{\ln \left(\frac{\lambda_{1}}{\lambda}\right)}{\ln \left(\frac{\lambda_{2}}{\lambda_{1}}\right)}\right)\right)^{2}+\left(\frac{\sigma\left(\tau_{2}\right)}{\tau_{2}} \cdot \frac{\ln \left(\frac{\lambda_{1}}{\lambda}\right)}{\ln \left(\frac{\lambda_{2}}{\lambda_{1}}\right)}\right)^{2}\right)^{1 / 2}$

where $\sigma\left(\tau_{i}\right)(\mathrm{i}=1 ; 2)$ is the uncertainty on AERONET optical thickness $\tau_{i}$ at wavelength $\lambda_{i}(440$ or $675 \mathrm{~nm})$. This equation can be written since error sources are independent thanks to the different filter channels of the sun photometer. The AERONET database gives a maximal absolute uncertainty of 0.02 for the optical thickness and for $n$ independent sunphotometer measurements the uncertainty is then given by

$\sigma\left(\tau_{i}\right)=\frac{0.02}{\sqrt{n}}$.

The resulting histogram of the 400 retrieved values of BER is given on Fig. 12 for the LESAA mean profiles between 

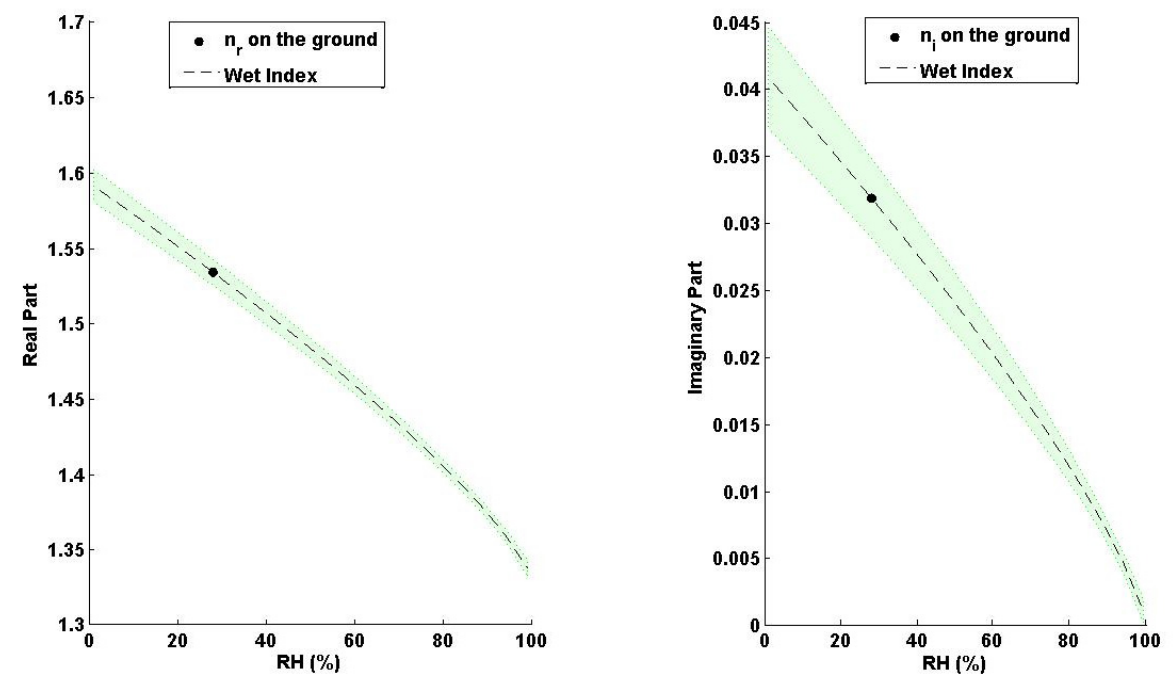

Fig. 13. Evolution of both the real and the imaginary part of ACRI at $532 \mathrm{~nm}$ as functions of the relative humidity (RH) based on observation performed between 12:00 and 13:00 UTC on 18 May. The dashed line represents the Hänel parametrisation curve and the filled circle shows the value retrieved on the surface level. The shaded area corresponds to the uncertainties linked to the error on ground computation and on RH.

12:00 and 13:00 UTC (Fig. 1). This procedure gives similar results for the other periods and leads to a standard deviation of BER as equal to $3.10^{-4} \mathrm{sr}^{-1}\left(1.210^{-3} \mathrm{sr}^{-1}\right)$, at 532 (355) $\mathrm{nm}$ with a positive bias less than $3 \cdot 10^{-5}\left(210^{-4}\right) \mathrm{sr}^{-1}$.

The resulting total uncertainties on $n_{r}, n_{i}$ and $\omega_{0}$ have been given in Table 1. As an illustration, the shaded area on Fig. 9 represents the calculated uncertainty $n_{i}$ as a function of the uncertainty on BER. Following the uncertainty study, the diurnal variability of the previous retrievals appears to be significant and may be due to the evolution of the aerosol chemistry and size distribution during the day.

\section{Water vapor effect}

\subsection{Parameterisation}

The increase in light-scattering by aerosols with RH at a specific wavelength has been considered to be an important parameter to estimate aerosol radiative forcing (Charlson et al., 1992; IPCC, 2001) and to understand the cause of visibility degradation due to aerosols (White and Roberts, 1977; Tang et al., 1981; Malm et al., 2003). As the relative humidity increases, condensation of water vapor may take place on the aerosol scatterers depending on their chemical composition (e.g. Tang and Munkelwitz, 1993). This phenomenon leads to an increase of the size of the particles (hygroscopic growth of aerosols). Apart from the change in size, hygroscopic aerosols experience a change in their refractive index and in several key optical properties (scattering and absorption coefficients, single scattering albedo, asymmetry parameter, and aerosol optical depth) that are relevant to aerosol radiative forcing estimates. When using lidar to remotely sense properties in the boundary layer, an accurate description of this effect becomes important where RH experiences a significant diurnal cycle. On a short time scale, significant changes in the lidar backscattering can be observed during the morning or evening transitions due to rapid changes in the boundary layer RH. This effect can lead to ambiguous interpretation of lidar backscatter data. An increase in static stability (less turbulent mixing) in the lower atmosphere or a modification of the emissions leading to changes in aerosol concentration can not be differentiated from an increase in the measured backscatter coefficient due to RH effect without an appropriate knowledge of the hygroscopic growth of the aerosols present over the lidar station.

To model the effect of water vapor on hydrophilic aerosols, we used the following relationships set up by Hänel (1976), describing aerosol growth and giving particle radius and refractive index for wet particles:

$r_{w}=r \cdot(1-\mathrm{RH})^{-\varepsilon}$

$n_{w}=n_{\mathrm{H}_{2} \mathrm{O}}+\left(n-n_{\mathrm{H}_{2} \mathrm{O}}\right) \cdot\left(\frac{r_{w}}{r}\right)^{-3}$

The suffix $w$ refers to wet conditions and RH is the relative humidity. $r$ and $n$ are the radius and the refractive index of aerosol particles, respectively, and $n_{\mathrm{H}_{2} \mathrm{O}}$ is the refractive index of pure water. The coefficient $\varepsilon$ depends on the considered type of aerosol and is taken as 0.26 according to Randriamiarisoa et al. (2006) over Paris. Figure 13 gives the evolution of $n_{r}$ and $n_{i}$ as a function of RH starting from our ground computation at $\mathrm{RH}=28 \%$. Given that the real part of the refractive index of pure water (1.33) is lower than the one 


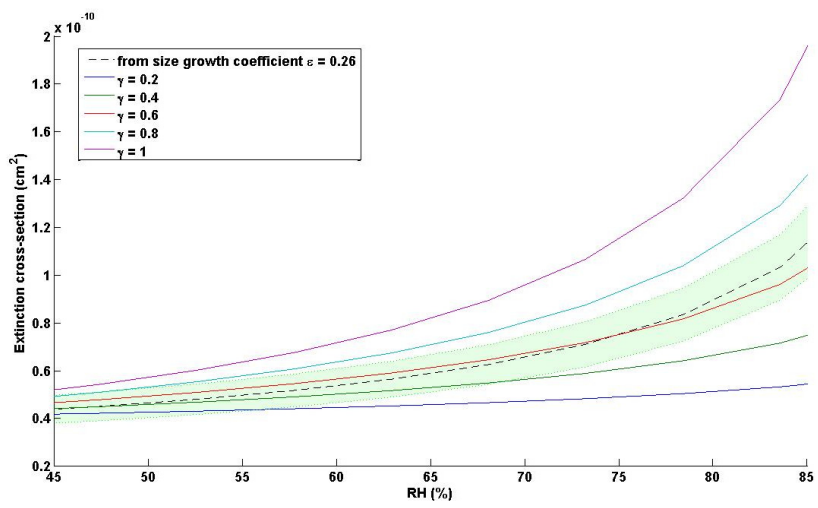

Fig. 14. Aerosol extinction cross section against the relative humidity (RH) based on observation performed between 12:00 and 13:00 UTC on 18 May. Colored solid lines represent the Hänel parametrisation curves with different scattering growth coefficients $\gamma_{e}$, whereas the dashed line shows the evolution of the cross section as calculated with Mie model and a size growth coefficient of 0.26 . The shaded area corresponds to the uncertainties.

associated to dry particles or measured on the ground and its imaginary part is almost zero $\left(10^{-8}\right), n_{r}$ and $n_{i}$ tend to decrease as the water uptake by the particles gets more and more important. Hänel (1976) also proposed a parametrisation of the scattering growth factor. It has been used by many investigators (Covert et al., 1972; Boucher and Anderson, 1995; Ross and Hobbs, 1998; Kotchenruther et al., 1999; Gasso et al., 2000; Randriamiarisoa et al., 2006) and is generally applied to the increasing part of the hysterisis cycle:

$$
\frac{\sigma_{\text {scatt }}(\mathrm{RH})}{\sigma_{\text {scatt }}\left(\mathrm{RH}_{\mathrm{ref}}\right)}=\left(\frac{(1-\mathrm{RH})}{\left(1-\mathrm{RH}_{\mathrm{ref}}\right)}\right)^{-\gamma}
$$

where $\sigma_{\text {scatt }}$ is the scattering cross-section and $\gamma$ is the scattering growth coefficient. Gasso et al. (2000) reported $\gamma$ between 0.27 and 0.6, Randriamiarisoa et al. (2006) found values between 0.47 and 1.35 for urban aerosols over Paris. In this study, an equivalent parameterisation focusing on extinction cross-sections has been used with an appropriate coefficient $\gamma_{e}$. A comparison between a computation of the previous equation and a Mie model using size distribution and refractive index with the associated size growth coefficient $\varepsilon=0.26$ enabled to retrieve $\gamma_{e}$. A Monte-Carlo method has been applied to assess the uncertainties considering the variations of 3 parameters: size distribution, complex refractive index and humidity rate whose absolute error is about $0.5 \%$. As shown in Fig. 14, the most convenient value for $\gamma_{e}$ is $0.55 \pm 0.05$ in the RH range [50\%-85\%]. This result is in agreement with values reported in the literature. Graphs of BER and $\omega_{0}$ are also given in Fig. 15. These results are in agreement with experimental results obtained on the ground with $\mathrm{RH}=28 \%$ and presented in Fig. 6. Consequently, sig- nificant variations in the lidar backscatter signal are expected when the hygroscopic growth of aerosols is pronounced.

\subsection{Application to the PBL}

Thanks to radiosounding data obtained in Trappes $\left(48^{\circ} 46 \mathrm{~N}\right.$, $2^{\circ} \mathrm{E}$ ), we try to understand to what extent relative humidity (RH) might influence the lidar-retrieved aerosol extinction coefficient.

Assuming a vertically homogeneous aerosol composition, optical properties obtained on 18 May have been used to simulate vertical extinction profiles for days where lidar profiles were simultaneously available (Figs. 16 and 17). The decreasing values of $n_{r}$ and $n_{i}$ with increasing RH would suggest a decrease in aerosol backscattering and absorption. But the size dependence dominates, leading to an increase in backscattering as RH increases: variations in refractive index are not large enough to counteract the $\mathrm{r}^{2}$ dependence of the variation in particles's cross-section due to size increase. Uncertainties on the simulated extinction profiles have been determined thanks to the corresponding uncertainties on $\gamma_{e}$ (Monte-Carlo approach in Sect. 6.1) and are represented by horizontal bars on Figs. 16 and 17. These bars are included in shaded areas standing for the variability of lidar-derived extinction profiles averaged over the corresponding day. A good agreement is found between lidar profiles and extinction profiles calculated with $\gamma_{e}$ coefficient. It is thus noteworthy that the hypothesis linking the vertical variability of extinction to RH in the atmospheric column is quite reliable. According to Fig. 16, modifications in the aerosol extinction coefficient are thus mainly due to RH effect rather than changes in aerosol concentration. On the 18 May (Fig. 16c), the constant BER hypothesis we made is justified because $\mathrm{RH}$ does not reach the deliquescence threshold in the column $(\mathrm{RH}<60 \%)$. However, the shape of aerosol extinction profiles is not always perfectly reproduced despite the satisfying overlapping between error bars and the lidar profile temporal variability. Hence, slight modifications in lidar profiles on the 26 May (Fig. 17b) cannot be precisely observed when the relative humidity is about constant in the PBL. The strongest divergence is observed on the 27 May (Fig. 17c) when a dust episode occurred. The accordance between profiles is fine except in the dust layer between $2.3 \mathrm{~km}$ and $3.2 \mathrm{~km}$ where the constant BER assumption in the atmospheric column is no longer valid. Variations in the atmospheric column for 27 May can be mainly ascribed to modifications in aerosol properties and concentration owing to air masses advection carrying dusts. The most important error bars observed on Fig. $17 \mathrm{a}$ are mainly due to the high variability of aerosol number concentration for the 25 May.

An altitude-dependent BER would have been particularly appreciated in this study but the lack of a Raman lidar leads us to suppose a constant BER in the atmospheric column. This hypothesis is not however to be discarded since simulated extinction profiles are in agreement with lidar-derived 

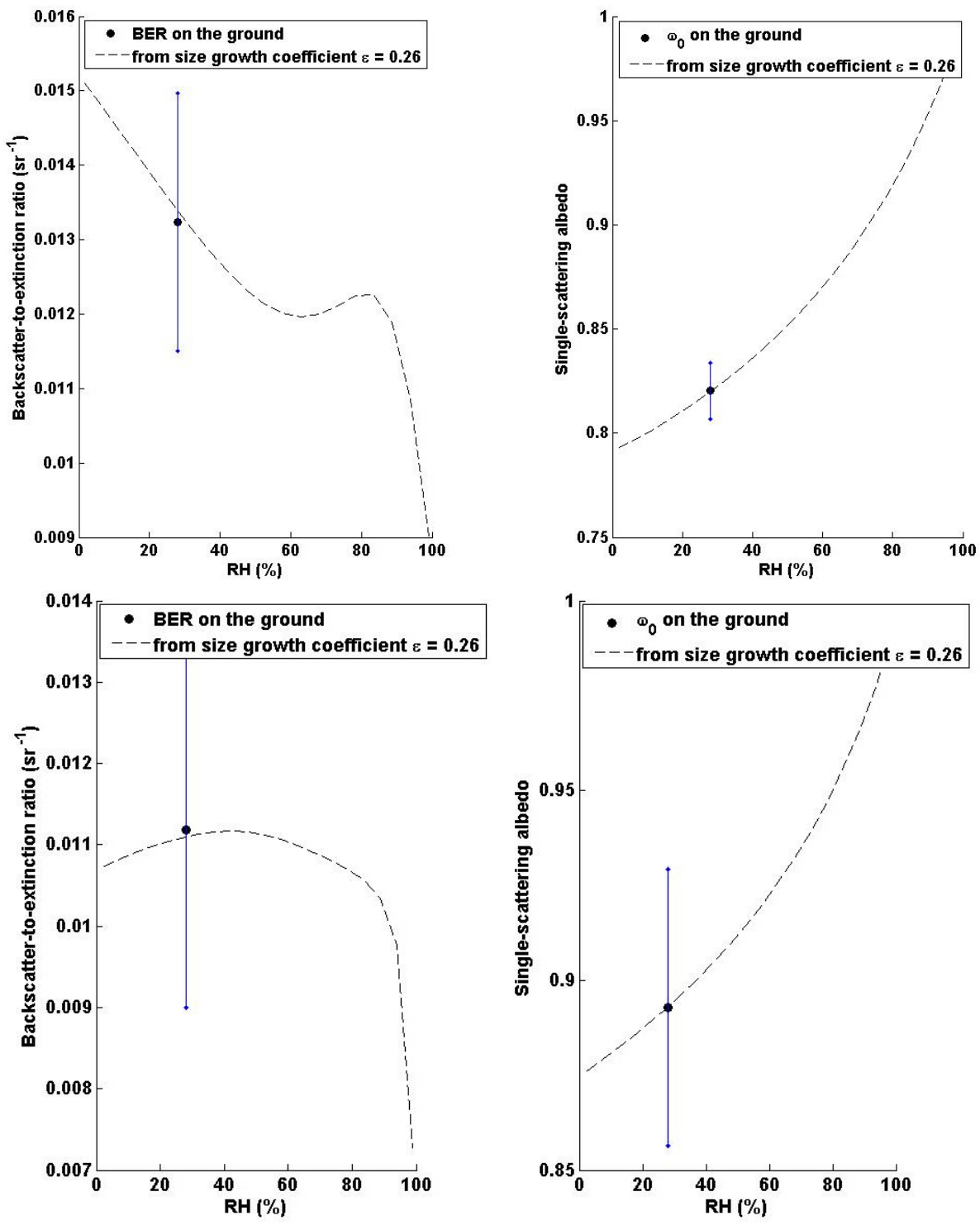

Fig. 15. Evolution of BER (left) and $\omega_{0}$ (right) with increasing relative humidity (RH) at $532 \mathrm{~nm}$ (a) and $355 \mathrm{~nm}$ (b). The dashed line represents Mie model computation with aerosol ground size distribution, complex refractive index and a size growth coefficient of 0.26 . The filled circle shows the value retrieved on the surface for measurements obtained between 12:00 and 13:00 UTC on 18 May. The vertical bars represent the standard deviation associated with surface measurements in the same period.

extinction coefficient profiles. Flamant et al. (2000) assessed uncertainties in the BER profile on the error in the extinction profile. They derived the particulate BER from modal diameters and refractive indices in literature introducing them into a Mie code. They showed that errors on lidar-derived extinction coefficient values throughout the lower troposphere are mainly due to the error on the reference extinction coefficient (about 20\%) rather than the error on BER profile (about 5\% in the plume). Furthermore, BER does not rapidly evolve with increasing RH. Calculations of the relative variation BER as a function of RH have been performed at $355 \mathrm{~nm}$ for RH comprised between $30 \%$ and $80 \%$. In this range, BER shows variations lower than $10 \%$.

On the other hand the same method has been applied with AERONET-retrieved aerosol size distribution associated with $\varepsilon=0.26$. Similar extinction profiles have been computed according to $\mathrm{RH}$ profile and starting from a relative humidity equivalent value $\mathrm{RH}_{e q}$ given by 

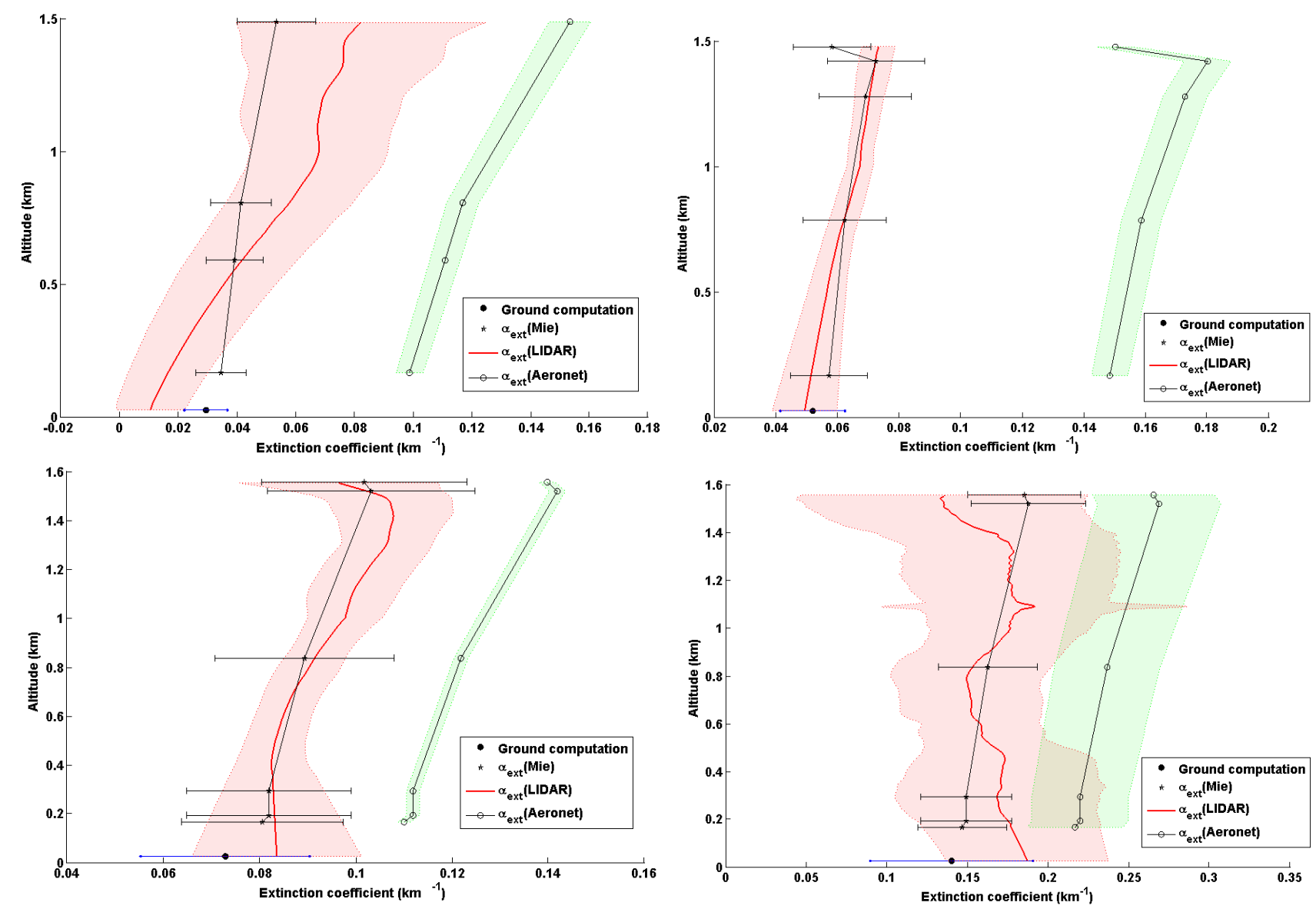

Fig. 16. Profiles of the aerosol extinction coefficient obtained between 12:00 and 13:00 UTC by lidar (red), ground size distribution (black) and Aeronet size distribution (green). Colored solid lines represent the mean profile obtained during the period and shaded areas or horizontal lines show their respective standard deviation. The mean extinction value retrieved on the ground level is given with a circle and its standard deviation with a horizontal bar. From left to right and top to bottom: 10 May at $532 \mathrm{~nm}$ (a), 12 May at $532 \mathrm{~nm}$ (b), $18 \mathrm{May}$ at $532 \mathrm{~nm}$ (c), 22 May at $532 \mathrm{~nm}(\mathbf{d})$.

$\mathrm{RH}_{e q}=\frac{\int_{0}^{\text {PBLtop }} \mathrm{RH}(z) \cdot \alpha(z) d z}{\int_{0}^{\text {PBLtop }} \alpha(z) d z}$,

which AERONET ACRI and size distribution have been determined with.

The profiles calculated from AERONET data cannot converge towards lidar-derived vertical extinction and the corresponding uncertainties lie apart from lidar variability. A likely influence of size distribution on scattering crosssections has to be investigated to explain such divergent results with AERONET data.

Hence, we performed a sensitivity analysis on AERONET size distribution so as to compare and discuss our results. Starting from volume concentration values in each size bin, we have converted the size distribution $\frac{d V}{d \ln r}$ given by Almucantar inversion in log-normal modes leading to the de- termination of number size distribution parameters (Seinfeld and Pandis, 1998). Large differences are observed between size distributions obtained on the ground level and from AERONET retrieval. Such discrepancies on size distribution yield divergent optical efficiencies. On the ground level, the accumulation mode centered at $0.1 \mu \mathrm{m}$, representing only $8 \%$ of the total number of particles, is responsible for the extinction efficiency by $90 \%$. The accumulation mode with a modal radius close to $0.1 \mu \mathrm{m}$ is highly predominant with Almucantar retrieval (80\% of optical efficiency), which does not seem able to manage the detection of very small particles with a radius lower than $50 \mathrm{~nm}$. Besides almost all aerosols measured in the atmospheric column seem to be shift towards the accumulation mode: this mode contains indeed $98 \%$ of the total number of particles. Conversely, no coarse mode was observed from in situ measurements at the ground level. Coarse mode in AERONET case is notwithstanding responsible for $20 \%$ of the aerosol 

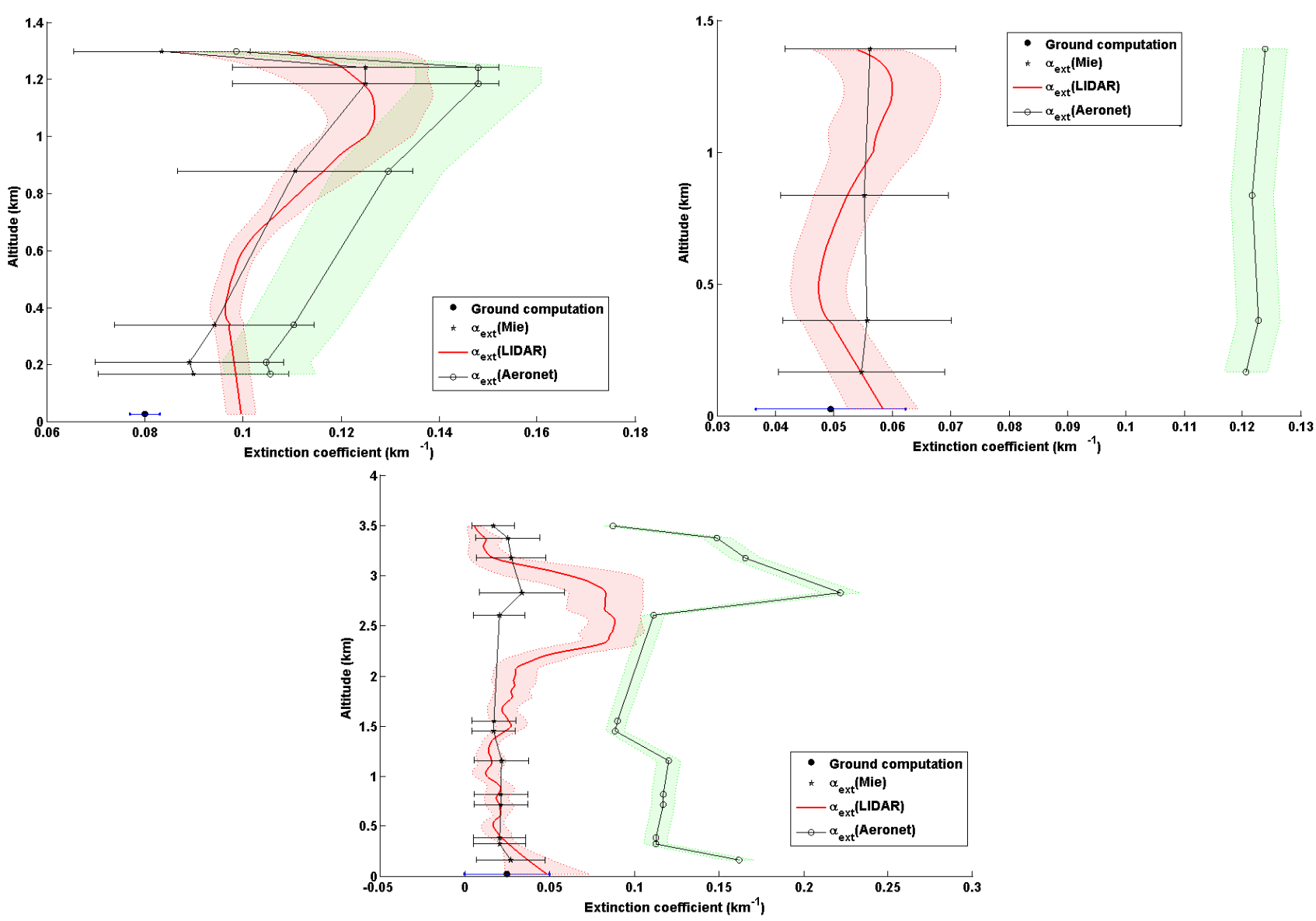

Fig. 17. Profiles of the aerosol extinction coefficient at $532 \mathrm{~nm}$ obtained between 12:00 and 13:00 UTC by lidar (red), ground size distribution (black) and Aeronet size distribution (green) in the case where divergence were observed. Colour solid lines represent the mean profile obtained during the period and shaded areas or horizontal lines show their respective standard deviation. The mean extinction value retrieved on the ground level is given with a circle and its standard deviation with a horizontal bar. From top to bottom: 25 May (a), 26 May (b), 27 May (c).

extinction. Quinn and Coffman (1998) underlined that the sampling of coarse aerosols is often a limitation in computing scattering from in situ data. As a consequence, AERONET size distribution is much more optically efficient: a factor 5 is observed on scattering cross-sections. It suggests divergent results for the previous comparisons based on lidar aerosol extinction profile retrieval, which are more favourable to the aerosol size distribution retrieved from in situ measurements. We should notice that the expected accuracy for $\frac{d V}{d \ln r}$ is 15$25 \%$ for $0.1 \mu \mathrm{m}<\mathrm{r}<7 \mu \mathrm{m}$ and $25-100 \%$ for $\mathrm{r}<0.1 \mu \mathrm{m}$ and $\mathrm{r}>7 \mu \mathrm{m}$ (Dubovik et al., 2000) and that the presence of low optical thicknesses does not guarantee accurate Almucantar retrievals (Sect. 2.2). Note that size distribution has a huge impact on vertical extinction profiles but only slight influence on optical ratios BER or $\omega_{0}$ (Figs. 6 and 11).

\section{Conclusion}

Ground based in situ and active/passive remote sensor measurements were performed in Paris to study the anthropogenic aerosols in such a megacity. We have presented an assessment of the aerosol complex refractive index at the ground level using the synergy between lidar, sunphotometer and in situ measurements. Our study based on the LISAIR campaign reveals the important climatic impact related to a significant imaginary part of $\sim 0.028(0.044)$ at 355 (532) $\mathrm{nm}$ and thus to a single-scattering albedo lower than 0.9 . This lead to heating rates close to $1 \mathrm{~K} /$ day in Paris intramuros PBL (evaluation with STREAMER (Key, 2001) already performed during INDOEX (Leon et al., 2002) and for spaceborne active/passive coupling on dusts (Berthier et al., 2006)) and thus to a change in dynamical equilibrium conditions of the urban boundary layer which are bound to influence pollutant dispersion. This new approach using lidar 
measurements has appeared to be a relevant tool to assess aerosol optical properties in urban areas and offers new perspectives for aerosol pollution studies above megacities. The knowledge of the aerosols properties in the urban PBL will be very useful to best understand the climate variability in the big cities due to their pollutant emissions.

Acknowledgements. This LISAIR program was funded by the city hall of Paris and the Commissariat à l'Energie Atomique (CEA). Part of this research was also funded by the French PRIMEQUAL-2 program. The authors would like to thank K. Oikonomou and J. Sciare for their help in the aerosol chemistry analyses.

Edited by: A. Lambert

\section{References}

Ackerman, F. and Chung, H.: Radiative effects of airborne dust and regional energy budget at the top of the atmosphere, J. Appl. Meteorol., 31, 223-233, 1992.

Ackerman, T. P. and Toon, O. B.: Absorption of visible radiation in atmosphere containing mixtures of absorbing and non absorbing particles, Appl. Opt., 20, 3661-3667, 1981.

Anderson, T. L., Masonis, S. J., Covert, D. S., Charlson, R. J., and Rood, M. J.: In situ measurement of the aerosol extinction-tobackscatter lidar ratio at a polluted continental site, J. Geophys. Res., 105(D22), 26 907, doi:10.1029/2000JD900400, 2000.

Angström, A.: The parameters of atmospheric turbidity, Tellus, 16, 64-75, 1964.

Baumgardner, D. G., Raga, G. B., Kok, G., Ogren, J., Rosas, I., Baez, A., and Novakov, T.: On the evolution of aerosols properties at a mountain site above Mexico City, J. Geophys. Res., 105, 22 243-22 253, 2000.

Bergin, M. H., Cass, G. R., Xu, J., Fang, C., Zeng, L. M., Yu, T., Salmon, L. G., Kiang, C. S., Tang, X. Y., Zhang, Y. H., and Chameides, W. L.: Aerosol radiative, physical, and properties in Beijing during June, 1999, J. Geophys. Res., 106, 17 969-17 980, 2001.

Berthier, S., Chazette, P., Couvert, P., Pelon, J., Dulac, F., Thieuleux, F., Moulin, C., and Pain, T.: Desert dust aerosol columnar properties over ocean and continental Africa from Lidar in-Space Technology Experiment (LITE) and Meteosat synergy, J. Geophys. Res., 111(D21202), doi:10.1029/2005JD006999, 2006.

Bissonnette, L. R.: Sensitivity analysis of lidar inversion algorithms., Appl. Opt., 25, 2122-2125, 1986.

Bodhaine, B. A., Ahlquist, N. C., and Schnell, R. C.: Threewavelength nephelometer suitable for aircraft measurements of background aerosol scattering coefficient, Atmos. Environ., 10, 2268-2276, 1991.

Bodhaine, B. A.: Aerosol absorption measurements at Barrow, Mauna Loa and the South Pole, J. Geophys. Res., 100, 89678975, 1995.

Bond, T. C., Charleson, R. J., and Heitzenberg, J.: Quantifying the emission of light-absorbing particles: Measurements tailored to climate studies, Geophys. Res. Lett., 25, 337-340, 1998.

Bond, T. C., Anderson, T. L., and Campbell, D.: Calibration and intercomparison of filter-based measurements of visible light absorption by aerosols, Aerosol Sci. Technol., 30, 582-600, 1999.
Boucher, O. and Anderson, L.: General circulation model assessment of the sensitivity of direct climate forcing by anthropogenic sulfate aerosols to aerosol size and chemistry, J. Geophys. Res., 100(D12), 26 117-26 134, 1995.

Cachier, H., Aulagnier, F., Sarda, R., et al.: Aerosol studies during the ESCOMPTE experiment: An overview, Atmos. Res., 74, 547-563, 2005.

Carlson, T. N. and Caverly, R. S.: Radiative characteristics of Saharan dust at solar wavelengths, J. Geophys. Res., 82, 3141-3152, 1977.

Carrico, C. M., Kus, P., Rood, M. J., Quinn, P. K., and Bates, T. S.: Mixtures of pollution, dust, sea salt, and volcanic aerosol during ACE-Asia: radiative properties as a function of relative humidity, J. Geophys. Res., 108(D23), 8650, doi:10.1029/2003JD003405, 2003.

Cattrall, C., Reagan, J. R., Thome, K., and Dubovik, O.: Variability of aerosol and spectral lidar and backscatter and extinction ratios of key aerosol types derived from selected Aerosol Robotic Network locations, J. Geophys. Res., 110(D10S11), doi:10.1029/2004JD005124, 2005.

Charlson, R. J., Schwartz, S. E., Hales, J. M., Cess, R. D., Coakley Jr., J. A., Hansen, J. E., and Hoffman, D. J.: Climate forcing by anthropogenic aerosols, Science, 255, 423-430, 1992.

Chazette, P., David, C., Lefrère, J., Godin, S., Pelon, J., and Mégie, G.: Comparative lidar study of the optical, geometrical, and dynamical properties of stratospheric postvolcanic aerosols, following the eruption of El Chichon and Mount Pinatubo, J. Geophys. Res., 100(D11), 23 195-23 207, 1995.

Chazette, P. and Liousse, C.: A case study of optical and chemical apportionment for urban aerosols in Thessaloniki, Atmos. Environ., 35, 2497-2506, 2001.

Chazette, P., Randriamiarisoa, H., Sanak, J., Flamant, C., and Pelon, J.: Airborne lidar for the surveyof the Paris aerosol production in the frame of ESQUIF program, in: Lidar Remote Sensing in Atmospheric and Earth Sciences, vol. 1. Defence R\&D Canada Valcartier, edited by: Bissonnette, L. R., Royet, G., and Vallée, G., Val-Bélair, Canada, pp. 173-175, 2002.

Chazette, P.: The monsoon aerosol extinction properties at Goa during INDOEX as measured with lidar, J. Geophys. Res., 108(D6), 4187, doi:10.1029/2002JD002074, 2003.

Chazette, P., Couvert, P., Randriamiarisoa, H., Sanak, J., Bonsang, B., Moral, P., Berthier, S., Salanave, S., and Toussaint, F.: Threedimensional survey of pollution during winter in French Alps valleys, Atmos. Environ., 39, 1035-1047, 2005 a.

Chazette, P., Randriamiarisoa, H., Sanak, J., Couvert, P., and Flamant, C.: Optical properties of urban aerosol from airborne and ground based in situ measurements performed during the ESQUIF program, J. Geophys. Res., 110, D02206, doi:10.1029/2004JD004810, 2005b.

Covert, D. S., Charlson, R. J., and Ahlquist, N. C.: A study of the relationship of chemical composition and humidity to light scattering by aerosols, J. Appl. Meteorol., 11, 968-976, 1972.

Cros, B., Durand, P., Cachier, H., et al.: An overview of the ESCOMPTE campaign, Atmos. Res., 69, 3-4, 241-279, 2004.

D'Almeida, G. A.: On the variability of desert aerosol radiative characteristics, J. Geophys. Res., 92, 3017-3026, 1987.

D’Almeida, G. A., Koepke, P., and Shettle, E. P.: Atmospheric Aerosols - Global Climatology and Radiative Characteristics, in: Atmospheric Aerosols. Global Climatology and Radiative Char- 
acteristics, edited by: Deepak, A., Hampton, VA, USA, pp561, 1991.

Dubovik, O., Smirnov, A., Holben, B. N., King, M. D., Kaufman, Y. J., Eck, T. F., and Slutsker, I.: Accuracy assessments of aerosol optical properties retrieved from AERONET sun and sky-radiance measurements, J. Geophys. Res., 105, 9791-9806, 2000.

Dubovik, O., Holben, B. N., Eck, T. F., Smirnov, A., Kaufman, Y. J., King, M. D., Tanre, D., and Slutsker, I.: Variability of absorption and optical properties of key aerosol types observed in worldwide locations, J. Atmos. Sci., 59, 590-608, 2002.

Durieux, E., Fiorani, L., Calpini, B., Flamm, M., Jaquet, L., and Van der Bergh, H.: Tropospheric ozone measurements over the greater Athens area during the MEDCAPHOT-TRACE campaign in Athens, Greece (20 August-20 September), Atmos. Environ., 32, 2141-2150, 1998.

Dye, J. E. and Baumgardner, D.: Evaluation of the forward scattering spectrometer probe: I. Electronic and optical studies, J. Atmos. Ocean. Technol., 1, 329-344, 1984.

Eleftheriadis, K., Balis, D., Colbeck, I., and Manalis, N.: Atmospheric aerosol and gaseous species in Athens, Greece, Atmos. Environ., 32, 2183-2191, 1998.

Ebert, M., Weinbruch, S., Hoffmann, P., and Ortner, H. M.: The chemical composition and complex refractive index of rural and urban influenced aerosols determined by individual particle analysis, Atmos. Environ., 38, 6531-6545, 2004.

Faxvog, F. R. and Roessler, D. M.: Carbon aerosol visibility vs particle size distribution, Appl. Opt., 17, 2612-2616, 1978.

Ferrare, R. A., Melfi, S. H. , Whiteman, D. N., Poellot, M., and Kaufman, Y. J.: Raman lidar measurements of aerosol extinction and backscattering, 2. Derivations of aerosol real refractive index, single-scattering albedo, and humification factor using a Raman lidar and aircraft size distribution measurements, J. Geophys. Res., 103, 19673-19689, 1998.

Flamant, C., Pelon, J., Chazette, P., Trouillet, V., Quinn, P. K., Frouin, R., Bruneau, D., Leon, J. F., Bates, T. S., Johnson, J., and Livingston, J.: Airborne lidar measurements of aerosol spatial distribution and optical properties over the Atlantic Ocean during a European pollution outbreak of ACE-2, Tellus B, 52(2), 662-677, 2000.

Gasso, S., Hegg, D. A., Covert, D. S., Collins, D., Noone, K. J., Oström, E., Schmid, B., Russel, P. B., Livingston, J. M., Durkee, P. A., and Josson, H.: Influence of humidity on the aerosol scattering coefficient and its effect on the upwelling radiance during ACE-2, Tellus, 52B, 546-567, 2000.

Hänel, G.: The properties of atmospheric aerosol particles as functions of the Relative humidity at thermodynamic equilibrium with the surrounding moist air, Adv. Geophys., 19, 73-188, 1976.

Hamonou, E., Chazette, P., Balis, D., Dulac, F., Schneider, X., Galani, E., Ancellet, G., and Papayannis, A.: Characterization of the vertical structure of Saharan dust export to the Mediterranean basin, J. Geophys. Res., 104, 22 257-22 270, 1999.

Hansen, A. D. A. and Novakov, T.: Real time measurements of aerosol black carbon during the carbonaceous species methods comparison study, Aerosol Sci. Technol., 12, 194-199, 1990.

Higurashi, A. and Nakajima, T.: Detection of aerosol types over the East China Sea near Japan from four-channel satellite data, Geophys. Res. Lett., 29(17), 1836, doi:10.1029/2002GL015357,
2002.

Hitzenberger, R. and Puxbaum, H.: Comparisons of the measured and calculated specific absorptiton coefficient for Vienna urban aerosols samples, Aerosol Sci. Technol., 18, 323-345, 1993.

Holben, B. N., Eck, T. F., Slutsker, I., et al.: AERONET - A federated instrument network and data archive for aerosol characterisation, Rem. Sens. Environ., 66, 1-16, 1998.

Hughes, H. G., Ferguson, J. A., and Stephens, D. H.: Sensitivity of a lidar inversion algorithm to parameters relating atmospheric backscatter and extinction, Appl. Opt., 24(11), 1609-1613, 1985.

Ignatov, A. M., Stowe, L. L., Sakerin, S. M., and Korotaev, G. K.: Validation of the NOAA/NESDIS satellite aerosol product over the North Atlantic in 1989, J. Geophys. Res., 100, 5123-5132, 1995.

Intergovernmental Panel on Climate Control (IPCC): Climate Change 2001, the Third Assessment Report of the IPCC, Cambridge Univ. Press, New York, 2001.

Kambezidis, H. D., Peppes, A. A., and Melas, D.: An environmental experiment over Athens urban area under sea breeze conditions, Atmos. Res., 36, 139-156, 1995.

Kaufman, Y. J., D. Tanré,Dubovik, O., Karnieli, A., and Remer, L. A.: Absorption of sunlight by dust as inferred from satellite and groundbased measurements, Geophys. Res. Lett., 28, 1479_ 1482, 2001.

Kent, G. S., Yue, G. K., Farrukh, U. O., and Deepak, A.: Modelling atmospheric aerosol backscatter at $\mathrm{CO} 2$ laser wavelengths. 1: Aerosol properties, modelling techniques, and associated problems, Appl. Opt., 22, 1655-1665, 1983.

Keskinen, J., Pietarinen, K., and Lehtimäki, M.: Electrical Low Pressure Impactor, J. Aerosol. Sci., 23(4), 353-360, 1992.

Key, J.: Streamer User's Guide, Cooperative Institute for Meteorological Satellite Studies, University of Wisconsin, 96 pp, 2001.

Kilsby C. G. and Smith M. H.: Comparison of the physical and optical properties of the atmospheric aerosol from airborne and surface measurements on the east coast of England, Atmos. Environ., 21, 2233-2246, 1987.

Kitchen, M. and Squires, E. C.: Aircraft observation of solar radiation in cloud free atmosphere, Boundary-Layer Meteorol., 29, 321-342, 1984.

Klett, J. D.: Stable analytical inversion solution for processing lidar returns, Appl. Opt., 20, 211-220, 1981.

Klett, J. D.: Lidar inversion with variable backscatter/extinction ratios, Appl. Opt., 24, 1638-1643, 1985.

Kotchenruther, R. A., Hobbs, P. V., and Hegg, D. A.: Humidification factors for atmospheric aerosol off the mid-Atlantic coast of United States, J. Geophys. Res., 104(D2), 2239-2252, 1999.

Kovalev, V. A.: Lidar measurement of the vertical aerosol extinction profiles with range-dependent backscatter-to-extinction ratios, Appl. Opt., 32, 6053-6065, 1993.

Landulfo, E., Papayannis, A., Artaxo, P., Castanho, A. D. A., De Freitas, A. Z., Souza, R. F., Vieira Junior, N. D., Jorge, M. P. M. P., Sanchez-Ccoyllo, O. R., and Moreira, D. S.: Synergetic measurements of aerosol over Sao Paulo, Brazil, using LIDAR, sunphotometer and satellite data during the dry season, Atmos. Chem. Phys., 3, 1523-1539, 2003, http://www.atmos-chem-phys.net/3/1523/2003/.

Lenoble, J.: Atmospheric Radiative Transfer, edited by: Deepak, A., Hampton VA, U.S.A., pp532, 1993.

Léon, J. F., Chazette, P., Pelon, J., Dulac, F., and Ramdria- 
marisoa, H., Aerosol direct radiative impact over the INDOEX area based on passive and active remote sensing, J. Geophys. Res., 107(D19), 8006, doi:10.1029/2000JD000116, 2002.

Liousse, C., Cachier, H., and Jennings, S. G.: Optical and thermal measurements of black carbon aerosol content in different environments: Variation of the specific attenuation cross-section, sigma, Atmos. Environ., 27A, 1203-1211, 1993.

Lurmann, F. W., Wexler, A. S., Pandis, S. N., Musarra, S., Kumar, N., and Seinfeld, J. H.: Modeling urban and regional aerosols: II. Application to California's South coast air basin, Atmos. Environ., 31, 2695-2715, 1997.

Mallet, M., Roger, J. C., Despiau, S., Dubovik, O., and Putaud, J. P.: Microphysical and optical properties of aerosol particles in urban zone during ESCOMPTE, Atmos. Res., 69, 73-97, 2003.

Malm, W. C., Day, D. E., Kreidenweis, S. M., Collett, J. L., and Lee, T.: Humidity-dependent optical properties of fine particles during the big bend regional aerosol and visibility observational study, J. Geophys. Res., 108(D9), 4279, doi:10.1029/2002JD002998, 2003.

Marley, N. A., Gaffney, J. S., Baird, J. C., Blazer, C. A., Drayton, P. J., and Frederick, J. E.: An Empirical Method for the Determination of the Complex Refractive Index of Size-Fractionated Atmospheric Aerosols for Radiative Transfer Calculations, Aerosol Sci. Technol., 34, 535-549, 2001.

Measures, R. M.: Laser Remote Sensing, Wiley-Interscience, New York, pp217, 1984.

Menut, L., Flamant, C., Pelon, J., and Flamant, P. H.: Urban boundary layer height determination from lidar measurements over the Paris area, Appl. Opt., 38(6), 945-954, 1999.

Menut, L., Vautard, R., Flamant, C., et al.: Measurements and modeling of atmospheric pollution over the Paris area: An overview of the ESQUIF project, Ann. Geophys., 18(11), 1467-1481, 2000.

Moores W. H.: Direct measurements of radiative and turbulent flux convergence in the lowest $1000 \mathrm{~m}$ of the convective boundary layer, Boundary Layer Meteorol., 22 283-22 294, 1982.

Moulin, C., Dulac, F., Lambert, C. E. , Chazette, P., Jankowiak, I., Chatenet, B., and Lavenu, F.: Long-term daily monitoring of Saharan dust load over ocean using Meteosat ISCCP-B2 data 2. Accuracy of the method and validation using sun photometer measurements, J. Geophys. Res., 102, 16 959-16969, 1997.

Müller, D., Wandinger, U., and Ansmann, A.: Microphysical particle parameters from extinction and backscatter lidar data by inversion with regularization: Theory, Appl. Opt., 38, 2346-2357, 1999.

Müller, D., Ansmann, A., Wagner, F., Franke, K., and Althausen, D.: European pollution outbreaks during ACE 2: Microphysical particle properties and single-scattering albedo inferred from multiwavelength lidar observations, J. Geophys. Res., 107(D15), 4248, doi:10.1029/2001JD001110, 2002.

Ouimette, J. R. and Flagan, R. C.: The extinction coefficient of multicomponent aerosols, Atmos. Environ., 16, 2405-2419, 1982.

Patterson, E. M., Gillete, D. A., and Stockton, B. H.: Complex index of refraction between 300 and $700 \mathrm{~nm}$ for Saharan aerosol, J. Geophys. Res., 82, 3153-3160, 1977.

Penner, J. E., Charlson, R. J., Hales, J. M., Laulainen, N. S., Leifer, R., Novakov, T., Ogren, J., Radke, L. F., Schwartz, S. E., and Travis, L.: Quantifying and minimizing uncertainty of climate forcing by anthropogenic aerosols, Bull. Am. Meteorol. Soc., 75,
375-400, 1994.

Quinn, P. K. and Coffman, D. J.: Local closure during the First Aerosol Characterization Experiment (ACE1): aerosol mass concentration and scattering and backscattering coefficients, J. Geophys. Res., 103, 15 575-15 596, 1998.

Randriamiarisoa H., Chazette, P., and Mégie, G.: The columnar retrieved single scattering albedo from $\mathrm{NO} 2$ photolysis rate, Tellus B, 56, 118-127, 2004.

Randriamiarisoa, H., Chazette, P., Couvert, P., Sanak, J., and Mégie, G.: Relative humidity impact on aerosol parameters in a Paris suburban area, Atmos. Chem. Phys., 6, 1389-1407, 2006, http://www.atmos-chem-phys.net/6/1389/2006/.

Ross, J. L., Hobbs, P. V., and Holben, B.: Radiative characteristics of regional hazes dominated by smoke from biomass burning in Brazil: Closure tests and direct radiative forcing, J. Geophys. Res., 103(D24), 31 925-31 941, 1998.

Sasano, Y., Browell, E. V., and Ismail, S.: Error caused by using a constant extinction/backscattering ratio in the lidar solution, Appl. Opt., 24, 3929-3932, 1985.

Seinfeld, J. H. and Pandis, S. N.: Atmospheric Chemistry and Physics, John Wiley \& Sons, New York, 408-440, 1998.

Sicard, M., Chazette, P., Pelon, J., Won, J. G., and Yoon, S. C.: Variational method for the retrieval of the optical thickness and the backscatter coefficient from multiangle lidar profiles, Appl. Opt., 41, 493-502, 2002.

Sinyuk, A., Torres, O., and Dubovik, O.: Combined use of satellite and surface observations to infer the imaginary part of refractive index of Saharan dust, Geophys. Res. Lett., 30(2), 1081, doi:10.1029/2002GL016189, 2003.

Sokolik, I. N., Andronova, A., and Johnson, T. C.: Complex refractive index of atmospheric dust aerosols, Atmos. Environ., 27, 2495-2502, 1993.

Sokolik, I. N. and Toon, O. B.: Incorporation of mineralogical composition into models of the radiative properties of mineral aerosol from UV to IR wavelengths, J. Geophys. Res. (D), 104(D8), 9423-9444, 1999.

Sokolik, I. N., Winker, D. M., Bergametti, G., Gillette, D. A., Carmichael, G., Kaufman, Y. J., Gomes, L., Schuetz, L., and Penner, J. E.: Introduction to special section: Outstanding problems in quantifying the radiative impacts of mineral dust, J. Geophys. Res. (D), 106(D16), 18 015-18 027, 2001.

Stelson, A.: Urban aerosol refractive index prediction by partial molar refraction approach, Environ. Sci. Technol., 24(11), 16761679, 1990.

Takamura, T., Sasano, Y., and Hayasaka, T.: Tropospheric aerosol optical properties derived from lidar, sunphotometer and optical particle counter measurements, Appl. Opt., 33, 7132-7140, 1994.

Tang, I. N., Wong, W. T., and Munkelwitz, H. R.: The relative importance of atmospheric sulfates and nitrates in visibility reduction, Atmos. Environ., 12, 2463-2471, 1981.

Tang, I. N. and Munkelwitz, H. R.: Composition and temperature dependence of the deliquescence properties of hygroscopic aerosols, Atmos. Environ., 27A, 467-473, 1993.

Todd, M. C., Martins, V., Washington, R., Lizcano, G., M'Bainayel, S., and Engelstaedter, S.: Optical properties of mineral dust from the Bodélé depression, Northern Chad during BoDEx 2005, J. Geophys. Res.,(D), in press, 2007.

Tomasi, C., Vitale, V., and Caroli, E.: Sahara dust program - II. De- 
termination of the vertical particulate mass loading by using extinction models based on Junge-type size distributions, J. Aerosol Sci., 14, 529-539, 1983.

Volz, F. E.: Infrared Optical Constants of Ammonium Sulfate, Sahara Dust, Volcanic Pumice, and Fly ash, Appl. Opt., 12, 564$568,1973$.
Wang, J., Christopher, S. A., Brechtel, F., Kim, J., Schmid, B., Redemann, J., Russell, P. B., Quinn, P., and Holben, B. N.: Geostationary Satellite Retrievals of Aerosol Optical Thickness during ACE-Asia, J. Geophys. Res., 108(23), 8657, doi:10.1029/2003JD003580, 2003.

White, W. H. and Roberts, P. T.: On the nature and origins of visibility-reducing aerosols in the Los Angeles air basin, Atmos. Environ., 11, 803-812, 1977. 